\title{
Macroeconometric Evaluation of Active Labour Market Policies in Germany - A Dynamic Panel Approach Using Regional Data*
}

\author{
Reinhard Hujer ${ }^{\dagger}$ \\ Goethe-University, Frankfurt \\ IZA, Bonn \\ $\begin{array}{cc}\text { Marco Caliendo } & \text { Christopher Zeiss } \\ \text { Goethe-University, Frankfurt } & \text { Goethe-University, Frankfurt }\end{array}$ \\ Uwe Blien ${ }^{\ddagger}$ \\ IAB, Nuremberg
}

First draft: February, 2002

This draft: October 11, 2002

\section{Working Paper}

\begin{abstract}
Most evaluation studies of active labour market policies (ALMP) focus on the microeconometric evaluation approach using individual data. However, as the microeconometric approach usually ignores impacts on the non-participants, it should be seen as a first step to a complete evaluation which has to be followed by an analysis on the macroeconomic level. As a starting point for our analysis we discuss the effects of ALMP in a theoretical labour market framework augmented by ALMP. We estimate the impacts of ALMP in Germany for the time period 1999-2001 with regional data of 175 labour office districts. Due to the high persistence of German labour market data the application of a dynamic model is crucial. Furthermore our analysis accounts especially for the inherent simultaneity problem of ALMP. For West Germany we find positive effects of vocational training and job creation schemes on the labour market situation, whereas the results for East Germany do not allow profound statements.
\end{abstract}

Keywords: Evaluation, Active Labour Market Policy, Dynamic Panel Data Model.

JEL Classification: C33, E24, H43, J64, J68.

* The authors thank Sascha O. Becker, Björn Christensen and Anatoli Vassiliev for valuable comments. We are indebted to Stephen Bond and Frank Windmeijer for a fruitful discussion and their help with the implementation of the dynamic panel data estimators. The paper has also benefited from several comments during the 5th IZA Summer School in Labour Economics (Buch/Ammersee, Germany, April 15-21, 2002). A special thanks goes to Steffen Kaimer and Elisabeth Hummel for valuable help with the data-handling. All remaining errors are our own.

${ }^{\dagger}$ Reinhard Hujer is Professor of Statistics and Econometrics at the J.W.Goethe-University of Frankfurt and Fellow of the IZA, Bonn. Corresponding author: Reinhard Hujer, Department of Economics and Business Administration, Johann Wolfgang Goethe-University, Mertonstr.17, 60054 Frankfurt, Germany, e-mail: hujer@wiwi.unifrankfurt.de.

$\ddagger$ Uwe Blien is Director of the Research Department 3 at the Institute for Employment Research (IAB) in Nuremberg and Fellow of the IZA in Bonn, e-mail: uwe.blien@iab.de.

$\S$ Marco Caliendo is Research Assistant at the Chair of Statistics and Econometrics, J.W.Goethe-University of Frankfurt, e-mail: caliendo@wiwi.uni-frankfurt.de.

ฯChristopher Zeiss is Research Assistant at the Chair of Statistics and Econometrics, J.W.Goethe-University of Frankfurt, e-mail: zeiss@wiwi.uni-frankfurt.de. 


\section{Contents}

1 Introduction 1

2 Micro- and Macroeconometric Evaluation 2

3 Macroeconomic Analysis of Active Labour Market Policy 3

4 Active Labour Market Policy in Germany 6

4.1 Institutional Setup and Instruments f . . . . . . . . . . . . . . . . 6

4.2 The Dataset and the Importance of Regional Analysis . . . . . . . . . . . . . . 10

4.3 Previous Empirical Findings for Germany . . . . . . . . . . . . . . . . . . 11

5 Empirical Analysis 12

5.1 Specification and Estimation $\ldots \ldots \ldots \ldots \ldots \ldots \ldots \ldots$

5.2 Results . . . . . . . . . . . . . . . . . . . . . . . . . . . . 18

$\begin{array}{llr}6 & \text { Conclusion } & 27\end{array}$

$\begin{array}{lr}\text { A Tables } & 28\end{array}$

$\begin{array}{ll}\text { B Figures } & 34\end{array}$

$\begin{array}{ll}\text { C Instrumental Matrix } & 37\end{array}$ 


\section{Introduction}

In view of the immense spending on active labour market policies (ALMP) in Germany (about 43 bn DM in 2001) and their debatable success, the evaluation literature has been growing rapidly in recent years. ${ }^{1}$ Most studies focus on the microeconometric approach using individual data. The importance of this approach is straightforward and the framework for such an analysis is well developed. ${ }^{2}$ However, as the microeconometric approach usually ignores impacts on the nonparticipants, it should be seen as a first step to a complete evaluation which has to be followed by a macroeconometric analysis. Instead of looking at the effect on individual performance, we would like to find out if the ALMP represent a net gain to the whole economy. This is likely to be the case only if the total number of jobs is positively affected by ALMP.

Most macroeconometric evaluations of ALMP are based on panel data models, since a single time series for one country or region usual does not provide enough observations. Between these studies, two major strands can be distinguished. First, authors like e.g. Forslund and Krueger (1994) or Calmfors and Skedinger (1995) use variation in programme scale across regional units (jurisdictions) combined with data at the regional level to estimate the effects. Second authors like Jackman, Pissarides, and Savouri (1990), Layard, Nickell, and Jackman (1991) or OECD (1993) use variation in programme scale across different countries even though such an analysis might suffer from the heterogeneous policy measures between the countries. As we want to evaluate the effects of ALMP in Germany for the recent years, our analysis will use a regional data set that enables use to estimate the net effect of ALMP for Germany .

In 1998 the legal basis for the labour market policy in Germany has been changed to the new Social Code SGB III. Changes have been made not only in the objectives, like a more intensive focus on problem groups of the labour market, but also in the institutional organization of labour market policy, leading to decentralization and more flexibility in the regional allocation of resources to different measures. This decentralization allows an adjustment to the situation on the local labour markets on one hand, and requires, on the other hand, that any evaluation takes regional flexibility into stronger considerations than before. The importance of suitable data which allows to take regional heterogeneity into account has to be stressed. Especially in Germany this is problematic due to permanent adjustments in the regional delimitations of the labour office districts ('Arbeitsamtsbezirke'). In contrast to other evaluation studies, this is not problematic for us because for the time span under consideration, no such changes occurred.

The aim of the study is to add a new perspective to the evaluation of ALMP in Germany. This is done by using regional data to obtain macroeconomic or net effects of these measures. The remainder of this paper is organized as follows. In the next section we discuss the microand macroeconometric evaluation approaches. Highlighting the advantages and shortcomings of each approach makes clear their necessity as additional ingredients to a complete evaluation. Section 3 presents briefly the possible effects of ALMP in a macroeconomic framework. Following that, section 4 gives an overview of ALMP in Germany, discusses the importance of regional analysis and reviews the previous empirical findings from macroeconometric evaluations for Germany. Section 5 presents the empirical analysis, where we first present the dynamic panel

\footnotetext{
${ }^{1}$ See Hagen and Steiner (2000) or Hujer and Caliendo (2001) for extensive overviews regarding micro- and macroeconometric evaluations of ALMP in Germany.

${ }^{2}$ See e.g. Heckman, LaLonde, and Smith (1999) or Smith (2000).
} 
data estimation approach before we discuss our results. Finally, section 6 concludes and gives an outlook for further research.

\section{Micro- and Macroeconometric Evaluation}

The ideal evaluation process consists of three steps. First, the impact of the programme on the participating individual should be estimated. Second, it should be examined if the impacts are large enough to yield net social gains. Finally, it should be answered if this is the best outcome that could have been achieved for the money spent (Fay, 1996). We will discuss the first two-steps, namely the micro- and the macroeconometric evaluation.

The main question of microeconometric evaluations is if the interesting outcome variable for an individual is affected by the participation in an ALMP programme. That being done, the direct gain can be compared with the associated costs and the success of the programme can be judged. However, microeconometric approaches estimate in nearly all cases the effect of treatment on the treated. One important concept in this context is the stable unit treatment value assumption (SUTVA, Rubin, 1980). One implication of SUTVA is that the effect of the intervention on each individual is not affected by the participation decision of any other individual, i.e. the treatment effect for each person is independent of the treatment of other individuals. This assumption guarantees that average treatment effects can be estimated independently of the size and composition of the treatment population. Among other things SUTVA excludes cross effects or general equilibrium effects. Even though its validity facilitates a manageable formal setup, in practical applications it is frequently questionable whether it holds. Looking at the immense amounts spent on ALMP in Germany (for details see section 4) and the large scale of the programmes, spill-over effects on non-participants are very likely. ${ }^{3}$ Therefore the microeconometric approach is partial-analytic and should only be seen as one-step to a complete evaluation, or as Heckman (1999) puts it, microdata are no panacea and must be used in conjunction with aggregate time-series data to estimate the full general-equilibrium consequences of policies.

The main problem is here that a positive effect on the individual level need not to be positive on the aggregate level. Particularly ALMP is often suspected to have a positive effect on the individual level but a zero or even a negative effect for the whole economy. In this context, deadweight losses and substitution effects have received substantial attention in the literature (see e.g. Layard, Nickell, and Jackman (1991) or OECD (1993)). If the outcome of the programme is not different from what would have happened in its absence, we talk about a deadweight loss. A common example is the hiring from the target group that would have occurred also without the programme. If a worker is taken on by a firm in a subsidized job instead of an unsubsidized worker who would have been hired otherwise, we talk about a substitution effect. The net short-term employment effect in this case is zero. Such effects are likely in the case of subsidies for private-sector work. There is always a risk that the employers hold back ordinary job creation in order to be able to take advantage of the subsidies. In order to minimize this danger, a principle of additionality may be imposed. Another problem might

\footnotetext{
${ }^{3}$ If we look at the typical small-scale U.S. programmes on the other hand, the occurrence of such effects is less likely.
} 
be that ALMP may crowd out regular employment. This can be seen as a generalization of the so called displacement effect. This effect typically refers to displacement in the product market, e.g. if firms with subsidized workers may increase output, but displace (reduce) output among firms who do not have subsidized workers. Calmfors (1994) also stresses the importance of tax effects in the sense that programmes have to be financed by taxes which distort the choices of both participants and non-participants.

To see how problems can arise through the neglect of such effects let us discuss an example. As the outcome variable of interest in Germany is usually the employment situation of participating individuals, we consider a wage subsidy programme that aims to increase the employment probability of long-term unemployed, by giving employees a subsidy if they hire an individual out of the target group. The usual microeconometric approach analyses the effects on the labour supply side of the market by looking at the individual's performance. So if the individual gets a job because of the subsidy, the programme was a success. The shortcoming is, however, the possible occurrence of substitution or displacement effects, e.g. if an unsubsidized worker is fired to hire a subsidized worker. Hujer, Caliendo, and Radic (2001) suggest estimating the success of wage subsidies on the labour demand side of the market by looking at the employment situation within the firm. Doing so, substitution effects within the firm already 'net out' and give a clearer picture of the net effects. Displacement effects between firms, however, cannot be detected with this approach. Clearly, these effects have to be taken into account if one intends to make statements about the net effect of ALMP.

\section{Macroeconomic Analysis of Active Labour Market Pol- icy}

The estimation of macroeconomic effects is not straightforward, and compared to the number of micro-analyses the existing literature is relatively small. The major obstacle, however, is that a macroeconometric analysis of ALMP should be based on a theoretical framework that explains the relevant labour market variables (e.g. regular employment or unemployment). Thereby the main problem is not the availability of an appropriate theory but the availability of suitable data in order to implement the theory in an econometric model.

Considering the available theories, the question arises which theoretical framework is appropriate for the analysis of ALMP. Leaving aside the traditional way of 'cheating the Phillips curve', i.e. improving the unemployment-inflation trade-off and thereby reducing the nonaccelerating inflation rate of unemployment (Baily and Tobin, 1977), a model is needed that generates a positive equilibrium unemployment rate and is also capable of incorporating ALMP. For the theoretical analysis of ALMP the two most used models are the Layard and Nickell (1986) framework and the search model framework (see e.g. Pissarides (2000)). Both models differ by their primary reason for equilibrium unemployment. In the Layard and Nickell framework, unemployment is generated through a wage setting process that pushes the wage rate over the equilibrium rate generated by labour demand and labour supply. One possible explanation for these wage distortions is the power of unions in the wage bargaining process or efficiency wages.

The Layard and Nickell framework is particularly suitable to consider the effects of ALMP on labour markets where wage distortions are a serious problem. 
Search models on the other hand assign the cause of unemployment to a time and cost consuming matching process. The matching process serves as a proxy for the differences in the geographic and skill characteristics between the vacant jobs and the job seekers. Therefore the matching process can be used to summarize mismatch problems and structural imbalances on the labour market. Due to the traditional intention of ALMP to overcome these problems, the matching process should be one important aspect for the analysis of ALMP. Theoretical considerations based on the impacts of ALMP in these two frameworks are given for example by Johnson and Layard (1986), Holmlund and Linden (1993) or Calmfors and Lang (1995). For the analysis of ALMP clearly a combination of both frameworks as presented by Calmfors and Lang (1995) is useful, since mismatch and wage distortions are problems of the labour market especially in Germany. Calmfors (1994) and Calmfors, Forslund, and Hemström (2002) identified within such a theoretical framework various effects of ALMP. In the following we will briefly present the most important ones.

Effects on the Matching Process ALMP can improve the matching process through several channels. First, ALMP can improve the active search behaviour of the participants. Second, ALMP can speed up the matching process by adjusting the structure of the labour supply to demand. Here we primarily think of retraining programmes that adapt the skills of the unemployed to the requirements of the vacant jobs. Third, the participation in an ALMP programme can serve as a substitute for work experience that reduces the employer's uncertainty about the employability of the job applicant.

If ALMP can improve the matching process, the question is what are the effects on regular employment or the wages. First of all an improved matching process means that for a given stock of vacancies there is a greater inflow into employment. ${ }^{4}$ Furthermore, the improved matching process reduces the average duration a vacancy remains unfilled. Since this reduces the costs of maintaining a vacancy firms provide more vacancies which is equivalent to an increase in the labour demand. The same effect also improves the firm's position in a wage bargaining process, since the firm can expect to fill a vacancy much quicker if a worker was laid off. Therefore the improved matching process also leads to a reduction of the wage rate.

ALMP programmes are also expected to have negative effects on the matching process, i.e. so called locking-in effects. If a participation in an ALMP programme is associated with full time employment, there might be insufficient time for actively searching a regular job. In this case the search effectiveness of the participants is lower than the search effectiveness of the openly unemployed (Holmlund and Linden, 1993). Since this locking-in effect vanishes at the moment when the programme expires, the question is if the positive effects on the search effectiveness persist after the participation has ended.

Effects on Welfare of the Unemployed If an ALMP programme rises the re-employment probability or if the compensation level is higher than the unemployment benefits, the ALMP programme rises the expected welfare of the unemployed. This is caused by the fact that an unemployed person faces a positive probability to being placed into a programme and thus faces a rise in the expected income. In the context of a wage bargaining process this is the same

\footnotetext{
${ }^{4}$ This is equivalent to an inward shift of the Beveridge Curve.
} 
as an increase of the fallback income, i.e. the income that is obtained if the bargaining fails and the worker becomes unemployed (Layard, Nickell, and Jackman, 1991). The rise of the fallback income leads to a higher outcome for the wage rate, since the position of the workers in the bargaining process is improved. This effect of ALMP on the wage pressure is indeed not avoidable, since every improvement of the situation of the unemployed is connected with a reduction of the welfare losses.

Effects on the Competition in the Labour Market ALMP (especially training programmes) are expected to improve the skills of the participants, i.e. to make the participants more competitive. This means not only that there is an improved competition between the unemployed but also an improvement of the competition between the employed and the unemployed, i.e. between the insiders and the outsiders. Additionally, ALMP can affect the competition if it stimulates the participants to search more actively (i.e. to counteract the discouraged worker effect) or it helps to rise the labour force participation. In both cases there is a rise in the effective labour supply, that leads to a reduction of the wage rate.

Effects on the Productivity ALMP programmes that improve the skills of the participants or serve as a substitute for work experience, can be expected to improve or to maintain the productivity of the participants. Considering a conventional labour demand condition, a rise in the productivity would lead to an increase of employment for a given wage rate. Calmfors (1994) notes that the rise in the productivity is not self evident, because on the other hand there is the opportunity to produce the same output with fewer but more efficient workers. Additionally, Calmfors, Forslund, and Hemström (2002) note that the rise in the productivity of the participants may also have a wage rising effect through a rise in the reservation wage of the participants.

In order to set up the econometric model for the evaluation, we can use the preceding discussion to find the relevant relationships. In particular, theory suggests that there are effects on the matching process, on employment and on the wage rate. Therefore, a straightforward empirical implementation would be the estimation of a matching function (see e.g. Boeri and Burda (1996)) or a wage equation (see e.g. Calmfors and Forslund (1991)). Unfortunately, data limitations do not allow us to estimate such structural relationships. For this reason we follow the strategy of Calmfors and Skedinger (1995) and base our empirical analysis on a reduced form relationship, explaining the total unemployment rate in the economy. Here we define the total unemployment as the stock of job seekers, i.e. the sum of openly unemployed and the programme participants. This is necessary to avoid estimating the bookkeeping effect, i.e. that a programme expansion leads automatically to a reduction in the stock of the openly unemployed.

The reduced form approach enables us to estimate the total net effect of ALMP, i.e the effect through all channels discussed above (Calmfors, Forslund, and Hemström, 2002).

Finally, it should be noted that only an empirical model using structural relationships makes it possible to estimate the different effects of ALMP, although the identification of more then one effect will in most cases fail due to data limitations. 


\section{Active Labour Market Policy in Germany}

We will start this section by giving a brief overview of the institutional setup and the instruments of ALMP in Germany, especially regarding the development after the introduction of the SGB III in the year 1998. Following that, we will describe the dataset used in our analysis, before we discuss the importance of regional analysis and the regional variation of the data at hand. Finally we review the previous empirical findings for Germany obtained from macroeconometric evaluations.

\subsection{Institutional Setup and Instruments}

Labour market policies in Germany are organized by the Federal Employment Office ('Bundesanstalt für Arbeit'). Up to 1998, the legal basis for the labour market policy in Germany has been the work support act ('Arbeitsförderungsgesetz', AFG), founded in 1969. From that point, the new Social Code SGB III ('Sozialgesetzbuch') took over this role. Changes have been made not only in the objectives, like a more intensive focus on problem groups of the labour market, but also in the institutional organization of labour market policy, leading to decentralization and more flexibility in the regional allocation of resources to different measures.

Since the data we analyse ranges from 1999 to 2001, we focus on the SGB III and discuss the AFG very briefly. A good overview of AFG's historical evolution can be found in Staat (1997). ${ }^{5}$ The improvement of the labour force structure, i.e. the adjustment of the labour supply to the changing labour demand, has been the primary goal in the early years. It was aimed to attend the continual growth of the economy that changed the labour market conditions permanently, with a continuous adjustment of the labour force structure to fulfill the new requirements. In detail, a short supply of jobs with specific (high-level) skills as well as an excess supply of jobs requiring low skills only was to be avoided. These goals had to be revised quite soon. At the end of 1973, the sharp rising unemployment rate in connection with the first oil price shock drove attention to the fight against this development. This becomes clear when we look at the participation structure of the ALMP. In the early 1970s, less than 15 per cent of all participants had been unemployed before participation, whereas in the 1980s this was the case for almost 80 per cent.

After some innovations and amendments, the AFG has been replaced by the SGB III in 1998. A good overview of the most relevant reforms can be found in Fitzenberger and Speckesser (2000). Sell (1998) presents an extensive discussion of the new SGB III, regarding especially the self-responsibility of employees for their own labour market success. Fertig and Schmidt (2000) explain and classify the different measures of employment promotion and explicitly distinguish between non-discretionary and discretionary measures. Brinkmann (1999) discusses aspects of decentralisation and regionalisation as well as the now mandatory output evaluations.

Whereas the AFG had been implemented under full employment conditions, the SGB III was born in a rougher economic situation, where labour market policy is affected by narrower budget constraints. Some of the AFG's objectives, like the securance of a high employment ratio and the avoidance of low-quality employment, were dropped. The most important goal $(\$ 7,3$

\footnotetext{
${ }^{5}$ The main goals can be found in $\S \S 1,2$ AFG and have been: (a) securance of a high employment ratio, (b) avoidance of low-quality employment, (c) improvement of the structure of the labour force, (d) promotion of mobility, (e) social goals and (f) promotion of target groups.
} 
SGB III) is the (re-)integration of problem groups in the regular labour market whilst using the resources in an efficient way ('Grundsatz der Wirtschaftlichkeit und Sparsamkeit').

As the government sees itself in a promoting role only, the SGB III places particular emphasis on the fact that employees have to act on their own authority regarding their labour market success. This comes together with a tightening of the reasonableness-clause ('Zumutbarkeitsklausel'), which for example makes it harder for unemployed to turn down job offers.

Besides the change of the objectives, there have been organizational changes, too, increasing the flexibility of ALMP on a regional and local level. The local employment offices are now allowed to allocate their budgets relatively freely to different measures. According to $\S \S 71 \mathrm{~b}, \mathrm{SGB}$ IV, several categories of ALMP must be financed by one single budget item ('Eingliederungstitel'), which is then assigned to the regional employment office. The new feature of the SGB III is now that the employment offices are free to set their priorities on how much weight to assign to each programme. This leaves the decision of the mix of instruments free to the particular regional branch of the Federal Employment Office (Brinkmann, 1999). This decentralization allows an adjustment to the situation on the local labour markets.

Furthermore, $10 \%$ of the budget can be used for 'free promotion' ('Freie Förderung', §10, SGB III), allowing a more individualized support. Each employment office has considerable flexibility to act with local focus, e.g. by implementing measures which are custom-made for the situation at the local labour market.

Another promising feature is the so-called 'Eingliederungsplan' to avoid long-term unemployment. Under this new plan, the local labour exchange and the unemployed have to establish which active measures or which action from the unemployed will help to avoid a drifting off into (long-term) unemployment within six months after the beginning of the unemployment spell.

Other interesting new measures, like the special programme to combat youth unemployment ('JUMP'), measures which are implemented in pathfinder regions and aim to promote the employment of low-qualified individuals or long-term unemployed ('CAST') as well as the reform law regarding the ALMP instruments ('JOB-AQTIV'), cannot be discussed here. For a comprehensive overview see Fitzenberger and Hujer (2002).

Another new point in the SGB III is the mandatory output evaluation. The employment offices are now required to draw up output evaluations ('Eingliederungsbilanzen', §11, SGB III), including most importantly the employment status of each participant some time after completion of a measure.

As our discussion made clear, any evaluation of the efficiency of labour market policy must give more consideration than before to regional flexibility and take into account the various support strategies developed by the employment offices (Brinkmann, 1999). This is what we are trying to do in section 5 .

Table 1 shows the spending on labour market policies in Germany from 1999 to 2001. Whereas in 1999 only $33.5 \%$ of the total spending have been dedicated to active measures, the share rose to $34 \%$ in 2001. In West Germany, the share of ALMP's rose from $27.6 \%$ to $30.3 \%$ whereas it decreased slightly in East Germany from around $42.9 \%$ to $40 \%$. 
Table 1: Spending on Labour Market Policies in Germany, 1999-2001

\begin{tabular}{|c|c|c|c|c|c|c|}
\hline & \multicolumn{2}{|c|}{1999} & \multicolumn{2}{|c|}{2000} & \multicolumn{2}{|c|}{2001} \\
\hline & $\begin{array}{l}\text { in bn } \\
\text { DM }\end{array}$ & $\begin{array}{l}\% \text { of } \\
\text { total }\end{array}$ & $\begin{array}{l}\text { in bn } \\
\text { DM }\end{array}$ & $\begin{array}{l}\% \text { of } \\
\text { total }\end{array}$ & $\begin{array}{l}\text { in bn } \\
\text { DM }\end{array}$ & $\begin{array}{l}\% \text { of } \\
\text { total }\end{array}$ \\
\hline \multicolumn{7}{|l|}{ Germany } \\
\hline Total Spending & 135.29 & & 125.96 & & 128.65 & \\
\hline Passive Labour Market Policies & 81.19 & 60.01 & 73.93 & 58.69 & 75.82 & 58.94 \\
\hline Active Labour Market Policies & 45.30 & 33.48 & 43.04 & 34.17 & 43.65 & 33.93 \\
\hline Vocational training (VT) & 13.20 & 9.76 & 13.31 & 10.57 & 13.66 & 10.62 \\
\hline Job Creation Schemes (JCS) & 7.81 & 5.77 & 7.20 & 5.71 & 5.82 & 4.52 \\
\hline Structural Adjustment Schemes (SAS) & 1.48 & 1.09 & 2.66 & 1.11 & 1.70 & 1.32 \\
\hline SAM-East for private firms (SAS-East) & 3.57 & 2.64 & 1.27 & 1.01 & 0.39 & 0.31 \\
\hline Free Support (FS) & 1.09 & 0.81 & 1.13 & 0.89 & 1.20 & 0.93 \\
\hline \multicolumn{7}{|l|}{ West Germany } \\
\hline Total Spending & 83.25 & & 78.14 & & 80.29 & \\
\hline Passive Labour Market Policies & 53.31 & 64.03 & 47.11 & 60.29 & 48.72 & 60.68 \\
\hline Active Labour Market Policies & 22.98 & 27.60 & 23.92 & 30.62 & 24.30 & 30.26 \\
\hline Vocational training (VT) & 7.78 & 9.34 & 7.94 & 10.16 & 8.19 & 10.20 \\
\hline Job Creation Schemes (JCS) & 2.14 & 2.58 & 2.00 & 2.56 & 1.69 & 2.10 \\
\hline Structural Adjustment Schemes (SAS) & 0.25 & 0.30 & 0.25 & 0.32 & 0.25 & 0.31 \\
\hline SAM-East for Private Firms (SAS-East) & 0.14 & 0.16 & 0.03 & 0.04 & 0.01 & 0.01 \\
\hline Free Support (FS) & 0.50 & 0.60 & 0.54 & 0.70 & 0.52 & 0.65 \\
\hline \multicolumn{7}{|l|}{ East Germany } \\
\hline Total Spending & 52.04 & & 47.83 & & 48.35 & \\
\hline Passive Labour Market Policies & 27.88 & 53.58 & 26.82 & 56.08 & 27.10 & 56.05 \\
\hline Active Labour Market Policies & 22.32 & 42.89 & 19.12 & 39.97 & 19.35 & 40.01 \\
\hline Vocational training (VT) & 5.43 & 10.43 & 5.37 & 11.24 & 5.47 & 11.30 \\
\hline Job Creation Schemes (JCS) & 5.66 & 10.88 & 5.20 & 10.87 & 4.13 & 8.55 \\
\hline Structural Adjustment Schemes (SAS) & 1.23 & 2.36 & 1.15 & 2.40 & 1.45 & 3.01 \\
\hline SAM-East for Private Firms (SAS-East) & 3.43 & 6.59 & 1.24 & 2.60 & 0.40 & 0.81 \\
\hline Free Support (FS) & 0.59 & 1.14 & 0.58 & 1.22 & 0.67 & 1.40 \\
\hline
\end{tabular}

Source: Bundesanstalt für Arbeit (2002)

One obvious reason for the limited success in switching resources into active measures, is the constantly high unemployment rate in East Germany (see Table 2). As unemployment benefits are entitlement-programmes and most active measures are discretionary in nature, the former increase automatically with a rising unemployment rate, whereas the latter are easier disposable.

The most important measures in 2001 have been vocational training ('Förderung der beruflichen Weiterbildung, VT) with 13.66 bn DM and subsidized employment, consisting of traditional job creation schemes ('Arbeitsbeschaffungsmaßnahmen', JCS) with 5.82 bn DM and structural adjustment schemes ('Strukturanpassungsmaßnahmen', SAS) with 1.70 bn DM.

In principle, public vocational training under the AFG comprised three types of training measures, namely further training ('Fortbildung'), retraining ('Umschulung') and training to familiarize with a new occupation ('Einarbeitung'). ${ }^{6}$ The first two types have been summarized in one item $(\S \S 77-96,153-159,517$ SGB III).

\footnotetext{
${ }^{6}$ See Hujer and Wellner (2000) for an overview of vocational training under the AFG.
} 
Table 2: Unemployment Rate in Germany, 1995-2001

\begin{tabular}{l|rrrrrrr}
\hline \hline & 1995 & 1996 & 1997 & 1998 & 1999 & 2000 & 2001 \\
\hline \hline Germany & 10.4 & 11.5 & 12.7 & 12.3 & 11.7 & 10.7 & 10.3 \\
West Germany & 9.3 & 10.1 & 11.0 & 10.5 & 9.9 & 8.7 & 8.3 \\
East Germany & 14.9 & 16.7 & 19.5 & 19.5 & 19.0 & 18.8 & 18.9 \\
\hline \hline
\end{tabular}

Source: Bundesanstalt für Arbeit (2002)

The latter is now part of the employment subsidies and will not be discussed here. ${ }^{7}$ The Federal Employment Office pays the costs of the training measures and a subsistence allowance ('Unterhaltsgeld') to the participants, which amounts to 60 per cent (67 with one or more children) of the previous net income (equal to unemployment benefit). The main goals are to re-integrate unemployed by improving their skills and turn away the danger of unemployment for employees at risk.

Let us now turn to subsidized employment programmes, consisting of traditional job creation schemes and structural adjustment schemes. JCS is the more important programme in West and East Germany and the spending in 2001 sum up to 5.82 bn DM. JCS ( $\S$ 260-271 SGB III) are normally only available to non-profit organisations. They should support activities which are of value to the society and additional in nature, that is without the subsidy they could not be executed. They include limited employment for long-term unemployed in projects to improve their labour market prospects. Even though JCS should be co-financed measures where between $30 \%$ and $75 \%$ of the costs are subsidies by the FEO and the rest is paid by the implementing institution (public or private legal entities, mainly municipalities), exceptions can be made in the direction of a higher subsidy-quota (up to 100\%). The subsidy is normally paid for 12 months but can be extended up to 24 and even 36 months if it is followed by regular employment. Priority is given to projects which improve the chances for permanent jobs, that support structural improvement in social or environmental services or that aim at the integration of extremely hard-to-place individuals.

Especially in East Germany, structural adjustment schemes ( $\S 272-279$ SGB III) play a prominent role, the spending amounting to 1.45 bn DM in 2001. Their goal is, analogous to JCS, the integration into regular employment, but less severe eligibility criteria apply to participants, so not only unemployed but also individuals threatened by unemployment may participate. The SAS consist of a wage subsidy equal to the average amount of unemployment allowance or assistance (including contributions to the social security system) which is paid on the Federal territory. The subsidy is typically paid for a maximum period of 36 (48) months. In East Germany, the SAS may be implemented by public institutions and private companies ('SAM Ost für Wirtschaftsunternehmen', SAS-East), whereas in West Germany only the first is possible. ${ }^{8}$

Looking at the distribution of the spending on the different measures shows considerable differences between West and East Germany. The dominantly used measure in the West is vocational training, where the expenditures amount to $8.19 \mathrm{bn} \mathrm{DM}$, corresponding to a share of

\footnotetext{
${ }^{7}$ See Hujer, Caliendo, and Radic (2001) for an overview.

${ }^{8}$ Since January 1998 SAS-East could also be requested in West-Berlin.
} 
$10.2 \%$ of the total spending. The next important measures are JCS with a share of $2.1 \%$ and SAS with $0.31 \%$.

In East Germany, the situation is much more balanced. Again, VT is the most important programme (5.47 bn DM, 11.3\%), but JCS (4.13 bn DM, 8.55\%) follows closely.

The discrepancy between both parts gets also clear if we look at Figures B.1 and B.2 in the appendix. They show the number of participants in the three most important programmes for West and East Germany from 4/1998 to 4/2001. In West Germany, on average 208.000 individuals participated in VT in every quarter, 55.000 in JCS and around 10.000 in SAS. The ratio between participants and unemployed has been 1:10. The situation in East Germany is as expected remarkably different. First of all, the participation in the different measures is more balanced. The most important measure is JCS with 137.000 participants on average, followed by SAS with 113.000 and VT with 131.000 and the ratio between participants and unemployed, has been 1:3.

After looking at the spending on the different measures and the participating individuals, it is also interesting to look at the average duration of the measures. This should give us important hints on the lag structure for our subsequent analysis. The average duration of the measures under consideration in 1999 lies between 8 and 10 months. JCS have the shortest duration with 8.3 months, followed by VT (8.4 months) and SAS with 9.8 months (Bundesanstalt für Arbeit, 2000).

\subsection{The Dataset and the Importance of Regional Analysis}

The data of this study refers to labour market regions defined by the administrative areas of the regional offices of the FEO. These are the adequate units of the analysis since, as we have seen, the regional offices take some important decisions concerning the mix of measures of active labour market policy. Furthermore, the allocation of funds is done by indicators calculated for these areas. These indicators are: The local job seeker rate (this is the unemployment rate extended by the rate of people participating in measures of active labour market policy), the growth rate of employment, the rate of long-term unemployed and the rate of people who leave unemployment to start a regular job (Blien, 2002). The sources of the data on unemployment and labour market policy measures used in this study are the internal administrative processes of the FEO. Recently administrative checks have shown that a special kind of data with the same origin is biased. Especially one variable which gives the figure of job placements done by the local offices of the BA is affected by this bias. This variable is not used in our study. There are no hints that there are similar problems with other variables. On the contrary, since the data are used for the allocation of funds and for administrative purposes associated with legal claims it could be expected that they are especially reliable. A detailed description of the data used can be found in the Tables A.1, A.2 and A.3 in the appendix.

A special difficulty of regional labour market analyses is that the regional units used, i.e. the administrative areas of the local offices, are not constant in time. Especially in East Germany their shape has been changed very often. Therefore it is not always clear whether e.g. a change in the number of unemployed registered in a special office is due to a change in the conditions on the local labour market or whether it is due to a change in the size of the area which refers to this office. For the time span in question 1999 - 2001 no such changes occurred. Therefore difficult 
procedures of recalculation could be avoided. The data base of this study is taken from the Pallas-reg system of the Institute for Employment Research. This system includes aggregated data originated by the administrative processes in the FEO and data from other sources. The advantage of these data is that the information is made consistent in the dimensions of time and space. This is not an easy task since there have been redefinitions of the data with respect to its content. The administrative processes changed during time according to different legal definitions and varying internal procedures of the Federal Employment Services. The data are prepared in a way that they can be used in scientific research.

The regional offices are free to decide between job creation schemes and measures of vocational training. Typically, in situations with great imbalances in the labour market, JCS are preferred to training measures, whereas in areas with low unemployment rates hardly any JCS are started. This can easily be seen from a comparison of the Figures B.3 and B.4 in the appendix. Figure B.3 shows the distribution of the job seeker rate in Germany. It is a very severe problem in the East. The lowest rates can be found in the south. Figure B.4 gives the relation between people participating in job creation schemes to those involved in measures of vocational training. The comparison of both maps shows the logic behind the regional distribution of the measures, since training is not very useful in areas where hardly any jobs are available. The size of the regional units used for the analyses can be seen from the figures. They show the great variation of the indicators used. The extreme values concerning the job seeker rate are $4.24 \%$ in Freising (Southern Germany, to the North of Munich) and 33.0\% in Sangershausen (Eastern Germany). Under the institutional structure of one country, very different labour market situations are discernible. Even if only Western Germany is regarded, there are high differences with $18.32 \%$ in Gelsenkirchen as the maximum value. These regional disparities provoke very different strategies of labour market policy. Regional analysis can be used to gain variance (Krugman, 1991) for economic analyses. The estimates can be done with far greater precision. Compared to data on individual participants of labour market policy schemes, regional data show e.g. indirect effects concerning the substitution of regular employment. The variation of conditions on the labour market is under the constraint of the same institutional setting. Only between East and West Germany there are some differences in the laws to be applied and there are, of course, major differences with respect to the history of both areas and the productivity of the economy.

\subsection{Previous Empirical Findings for Germany}

We will now give a brief overview of the empirical findings from macroeconometric evaluations for Germany on a regional level.

Büttner and Prey (1998) use yearly data (1986 to 1993) from 74 planning regions of West Germany to evaluate the effects of training programmes and public sector job creation on the labour market efficiency. They use a disequilibrium approach and their results suggest that training programmes have no effect and job creation programmes have a significant positive effect on the matching efficiency. Prey (1999) extends this work by additionally controlling for the regional age structure and recipients of social assistance and estimating separately for men

and women. She finds that VT increases (decreases) the mismatch for women (men), whereas JCS decreases the mismatch for men. 
Pannenberg and Schwarze (1998) use the data from 35 local labour office districts to evaluate training programmes in East Germany. They use monthly data from 1992 to 1994 and find that the programmes have negative effects on the regional wages.

Steiner, Wolf, Egeln, Almus, Schrumpf, and Feldotto (1998) examine the effects of vocational training on the labour market mismatch using the data from 35 local labour office districts in East Germany. They observe only very small effects on the matching efficiency which disappear in the long-run.

Schmid, Speckesser, and Hilbert (2000) use yearly data from 142 local labour office districts to estimate the effects of further training, retraining, public sector job creation and wage subsidies on long-term unemployment in the period 1994-1997. They find that job creation programmes reduce only 'short' long-term unemployment (6-24 months), whereas vocational training reduces long-term unemployment (> 24 months).

Hagen and Steiner (2000) evaluate vocational training, job creation schemes and structural adjustment schemes in East and West Germany using the data from local labour office districts. The time period under consideration differs and ranges from 1990-1999. The estimated net effects are not very promising as all measures increase unemployment in West Germany. Only SAS reduces the unemployment rate slightly in East Germany, whereas JCS and VT increase it, too.

Blien et al. (2002) analyse the effects of ALMP on the development of regional employment in Eastern Germany and find positive impacts. They use detailed data form the employment statistics and the time span of 1993-99. Their regional units are 112 districs ('Landkreise / kreisfreie Städte'). Their method is an econometric equivalent to conventional shift-share analysis (based on constrained regression), which is extended to include many determining variables.

\section{Empirical Analysis}

The empirical analysis exploits a pooled time-series cross-section data set for the German labour office districts. The time span ranges from the first quarter 1999 to the fourth quarter 2001, leaving us 12 observations for each labour office district. As discussed in section 4, the immense differences between the East and the West German labour market make it necessary to analyse both areas separately. The number of cross sections for West Germany are 141 and 34 for East Germany. ${ }^{9}$

\subsection{Specification and Estimation}

For the analysis of the effects of ALMP on the job seeker rate, the basic equation we want to estimate is

$$
c(L) s_{i t}=a_{0}+\sum_{j=1}^{3} a_{j}(L) \psi_{i t}^{j}+\sum_{k=1}^{K} b_{k}(L) x_{i t}^{k}+u_{i t},
$$

where $s_{i t}$ is the regional rate of total job seekers relative to the labour force, $\psi_{i t}^{j}$ (for $j=$ $1,2,3)$ is a measure for the ALMP programmes and $x_{i t}^{k}$ (for $\left.k=(1, \cdots, K)\right)$ is a set of $K$ other

\footnotetext{
${ }^{9}$ Due to data limitations, Berlin is excluded from the analysis.
} 
explanatory variables. As usual in the panel context, all variables are indexed by $t=(1, \cdots, T)$ as a time index and $i=(1, \cdots, N)$ is an index for the regions. $c(L)=1-c_{1} L-c_{2} L^{2}-\cdots-c_{p} L^{p}$, $a_{j}(L)=a_{j 0}+a_{j 1} L+a_{j 2} L^{2}+\cdots+a_{j q} L^{q}$ and $b_{k}(L)=b_{k 0}+b_{k 1} L+b_{k 2} L^{2}+\cdots+b_{k q} L^{q}$ are associated polynomials in the lag operator with $p$ and $q$ as the maximum lag, where $q$ need not be the same for all explanatory variables. The rate of total job seekers is given by the sum of unemployed and participants in ALMP programmes relative to the labour force. The ALMP programmes we analyse are divided into job creation schemes $P_{i t}^{1}$, structural adjustment schemes $P_{i t}^{2}$ and training programmes $P_{i t}^{3}$. Since the job seeker rate contains the ALMP participants, a direct usage of the participation rates (i.e. programme participants relative to the labour force) would bias our results. To avoid this, we follow Calmfors and Skedinger (1995) and utilize so called accommodation ratios to express the regional ALMP activity. The accommodation ratios are defined as the stock of participants in a specific type of programme relative to the total rate of job seekers, i.e.

$$
\psi_{i t}^{j}=P_{i t}^{j} /\left(U_{i t}+\sum_{k=1}^{3} P_{i t}^{k}\right)
$$

for $j=(1,2,3)$. For the further analysis, the ALMP accommodation ratios will be summarized as $\Psi_{i t}=\left[\psi_{i t}^{1}, \psi_{i t}^{2}, \psi_{i t}^{3}\right]$. Finally $X_{i t}=\left[x_{i t}^{1}, \cdots, x_{i t}^{K}\right]$ includes national variables like the national unemployment and vacancy rate, and seasonal dummies to control for cyclical and seasonal factors.

The imposed dynamic specification of equation (1) not only enables us to control for the high persistence of quarterly labour market data but also to analyse the time lag between a change of the ALMP activity and the associated impact on the regional job seeker rate. This is particularly advisable if we bear possible locking-in effects of ALMP programmes in mind. Our description of the German situation in section 4.1 has shown that the average duration of the programmes lies between 8 to 10 months. Therefore a lag of 4 quarters for the accommodation ratios is advisable. In particular, we will impose 4 lag's for the job seeker rate and for the ALMP measures.

Equation (1) can be seen as a reduced form relationship that explains the job seeker rate as a function of the ALMP measures and other variables. ${ }^{10}$

For the residual, we assume a conventional one way error-component structure:

$$
u_{i t}=\mu_{i}+v_{i t}
$$

with

$$
E\left(\mu_{i}\right)=0, E\left(v_{i t}\right)=0 \text { and } E\left(v_{i t} \mu_{i}\right)=0 . \text { for } i=1, \cdots, N \text { and } t=5, \cdots, T
$$

and

\footnotetext{
${ }^{10}$ Using the job seeker rate as dependent variable allows us to draw conclusions for the regular rate of employment which is defined as $n=1-s$. The use of the job seeker rate would be problematic if ALMP programmes would attract people from out of the labour force into the labour force. In this case there would be a movement in the job seeker rate that should not be interpreted as a programme effect. But since nearly all programme participants are placed from the stock of unemployed this problem is negligible.
} 


$$
E\left(v_{i t} v_{i g}\right)=0 \text { for } i=1, \cdots, N \text { and } g \neq t .
$$

Finally we follow Blundell, Bond, and Windmeijer (2000) and also impose a standard assumption concerning the initial conditions $s_{i 1}, s_{i 2}, s_{i 3}$ and $s_{i 4}$ :

$$
E\left(s_{i g} v_{i t}\right)=0 \text { for } i=1, \cdots, N, t=5, \cdots, T \text { and } g=1, \cdots, 4 .
$$

Furthermore it is reasonable to assume that $E\left(s_{i t} \mu_{i}\right) \neq 0$ and $E\left(\Psi_{i t} \mu_{i}\right) \neq 0$ because these regional variables should be expected to be correlated with the regional effect $\mu_{i}$. In contrast, $X_{i t}$ does not contain variables that are regionally specific and we can assume that $E\left(X_{i t} \mu_{i}\right)=0$

Due to the correlation of the regional variables with the regional specific effect a conventional OLS estimation would lead to biased results. Furthermore, in our dynamic specification with the lagged dependent as an explanatory variable also an usual within transformation is problematic. ${ }^{11}$ Particularly the within estimator in the dynamic panel data context is biased and its consistency depends on $T$ being large. ${ }^{12}$

To overcome these problems of the conventional estimators in the dynamic panel data context where the explanatory variables are correlated with the regional effect, we will utilize the firstdifferenced GMM estimator suggested by Arellano and Bond (1991) and the system GMM estimator suggested by Blundell and Bond (1998).

The moment conditions that are used to identify equation (1) depend heavily on the specification of the model and the theoretical considerations. Therefore we will now present the moment conditions that we set up for our estimations.

The first-differenced GMM estimator suggested by Arellano and Bond (1991) builds the moment conditions on the equations in first differences, where the regional effect is removed:

$$
c(L) \Delta s_{i t}=\sum_{j=1}^{3} a_{j}(L) \Delta \psi_{i t}^{j}+\sum_{k=1}^{K} b_{k}(L) \Delta x_{i t}^{k}+\Delta u_{i t} .
$$

For the lagged job seeker rate we can now set up the following linear moment conditions,

$$
E\left(s_{i t-g} \Delta u_{i t}\right)=0 ; \text { for } t=6, \cdots, T \text { and } 2 \leq g \leq t-1,
$$

where the beginning at $t=6$ is reasoned by the inclusion of 4 lags. This moment condition results from the assumed absence of serial correlation in $v_{i t}$ in (4) and the initial conditions in (5).

A major problem of the macroeconometric evaluation of ALMP is the interdependence between ALMP and the unemployment rate. With the intention of ALMP to counteract unemployment, it is most natural to think of the decision on how much money is spent on ALMP being determined by the unemployment rate. Generally, the level of ALMP activity is assumed to be determined by a policy reaction function where the unemployment rate is only one argument besides others (Calmfors and Skedinger, 1995). As our discussion in section 4.2 has

\footnotetext{
${ }^{11}$ See e.g. Baltagi (2001).

${ }^{12}$ For the bias and the consistency of the within estimator in dynamic models see for example Nickell (1981) and Ridder and Wansbeek (1990).
} 
shown, this is also true for Germany, as the allocation of funds to the local labour offices is done according to several indicators, including e.g. the job seeker rate and long-term unemployed.

As Calmfors and Skedinger (1995) note, one can hope that the utilization of accommodation ratios in order to measure the ALMP activity weakens the problem of interdependence, because it is a priori not clear if an increase of the unemployment rate leads to a more or less proportional increase in the programme participation. Since the unemployment rate is a major part of the job seeker rate, it is reasonable to assume that the job seeker rate and the accommodation ratios are determined simultaneously. Following this discussion, we assume that the ALMP accommodation ratios are endogenous, i.e. $E\left(\Psi_{i g} v_{i t}\right) \neq 0$ for $g \leq t$. These considerations and assumptions (4) and (5) enable us to build the following linear moment conditions analogously to the lagged dependent variable:

$$
E\left(\Psi_{i t-g} \Delta u_{i t}\right)=0 ; \text { for } t=6, \cdots, T \text { and } 2 \leq g \leq t-1
$$

For the explanatory variables in $X_{i t}$ we assume that they are strictly exogenous, i.e. $E\left(X_{i g} v_{i t}\right)=0$ for all $g, t$. In the case of strict exogenity, the full set of moment conditions is given by: $E\left(X_{i g} \Delta u_{i t}\right)=0$ for $t=6, \cdots, T$ and $1 \leq g \leq T$ (Blundell, Bond, and Windmeijer, 2000). But since $X_{i t}$ contains no regional information, this full set of moment conditions is not informative in order to identify the parameters in $b_{k}(L)$. Therefore we simply use the $\Delta X_{i t}$ to instrument themselves, i.e. we impose the following $K$ moment conditions:

$$
E\left(\Delta X_{i t} \Delta u_{i t}\right)=0 .
$$

In order to implement the first-differenced GMM estimator with the moment conditions (6), (7) and (8), we write the full set of moment conditions as

$$
E\left(\mathbf{Z}_{\mathbf{d i}}^{\prime} \Delta \mathbf{u}_{\mathbf{i}}\right)=0,
$$

where $\mathbf{Z}_{\mathbf{d i}}^{\prime}$ is defined in the appendix $\mathrm{C}$. The first-differenced GMM estimator then minimises the quadratic distance $\Delta \mathbf{u}^{\prime} \mathbf{Z} \mathbf{A}_{\mathbf{N}} \mathbf{Z}^{\prime} \Delta \mathbf{u}$, where $\mathbf{A}_{\mathbf{N}}$ is the weight matrix. Note that since all moment conditions are linear in the parameters, the minimum distance expression can be solved analytically. As weight matrix we use

$$
\mathbf{A}_{\mathbf{N}}=\left[N^{-1} \sum_{i=1}^{N} \mathbf{Z}_{\mathbf{i}}^{\prime} \Delta \mathbf{u}_{\mathbf{i}}\left(\beta_{1}\right) \Delta \mathbf{u}_{\mathbf{i}}\left(\beta_{1}\right)^{\prime} \mathbf{Z}_{\mathbf{i}}\right]^{-1},
$$

where $\boldsymbol{\Delta} \mathbf{u}_{\mathbf{i}}\left(\beta_{1}\right)$ are the residuals from a consistent one-step estimator $\beta_{1}$. This one-step estimator is calculated with the weight matrix $\mathbf{A}_{\mathbf{N}}=\left(N^{-1} \sum_{i} \mathbf{Z}_{\mathbf{i}}{ }^{\prime} \mathbf{H}_{\mathbf{i}}^{\mathbf{D}} \mathbf{Z}_{\mathbf{i}}\right)^{-1}$, where $\mathbf{H}_{\mathbf{i}}^{\mathbf{D}}$ is a $(T-5) \times(T-5)$ matrix with 2's on the main diagonal and -1's on the sub-diagonals and zeros otherwise (Arellano and Bond, 1991). If the $v_{i t}$ are i.i.d. disturbances, the one-step and two-step estimates of the first-differenced GMM estimator are asymptotically equivalent (Arellano and Bond, 1991).

As presented in Ahn and Schmidt (1995), the linear first-differenced GMM estimator does not utilize all moment conditions that result from assumption (2)-(5). Furthermore, Monte Carlo results from Blundell and Bond (1998) and Blundell, Bond, and Windmeijer (2000) have shown that in certain cases the first-differenced GMM estimator tends to be biased. As it was shown by Blundell and Bond (1998) and Blundell, Bond, and Windmeijer (2000), a poor 
performance of the first-differenced GMM estimator can result from a high persistent pattern in the dependent variable, or if the variance of the regional effect $\mu_{i}$ exceeds the variance of the residual $v_{i t}$. Unfortunately, both cases seem to be present in our model. First, it is well known that the unemployment rate is highly persistent. Second, we observe for West Germany a considerable variation in the regional job seeker rates (see Fig. B.3).

To overcome these drawbacks of the first-differenced GMM estimator, we also implement the system GMM estimator suggested by Blundell and Bond (1998). This system GMM estimator uses additional moment conditions for the equations in levels that result from restrictions on the initial conditions. These conditions relate to the assumption that the first differences of the dependent process is uncorrelated with the regional effect. Applied to our case this implies the following moment conditions for the job seeker rate

$$
E\left(u_{i t} \Delta s_{i t-g}\right)=0 ; \text { for } t=6, \cdots, T \text { and } g=1, \cdots, 4,
$$

where we regard for the inclusion of 4 lags in equation (1). ${ }^{13}$

Blundell, Bond, and Windmeijer (2000) have shown that if the dependent and the independent processes are mean stationary, these additional moment conditions for the equations in levels are valid, although the assumption of mean stationary is stronger then necessary. If our conditional model (1) has generated the $s_{i t}$ process for a sufficiently long time prior to our sample for any influence of the initial conditions to be negligible, $\Delta s_{i t}$ will be uncorrelated with the regional effect provided that $E\left(\Delta \Psi_{i t} \mu_{i}\right)=0$ (Blundell, Bond, and Windmeijer, 2000). Note that if $E\left(u_{i t} \Delta \Psi_{i t}\right) \neq 0$, obviously $\Delta s_{i t}$ would be correlated with $\mu_{i}$. Therefore we also need to assume that the $\Psi_{i t}$ process is uncorrelated with the regional effect in first differences. In this case the following moment conditions are valid.

$$
E\left(u_{i t} \Delta \Psi_{i t-g}\right)=0 ; \text { for } t=6, \cdots, T \text { and } g=1, \cdots, 4,
$$

where $g$ starts at 1 because we assume that $\Psi_{i t}$ is endogenously determined. ${ }^{14}$

For the remaining variables which are not determined by a regional specific component, we just impose the following $k$ moment conditions, i.e these variables are used to instrument themselves.

$$
E\left(u_{i t} X_{i t}\right)=0
$$

As noted by Blundell, Bond, and Windmeijer (2000), the linear moment conditions for the level equations render the nonlinear moment conditions suggested by Ahn and Schmidt (1995) as redundant. Therefore a system estimator using the full set of moment conditions can be implemented as a linear estimator. For the calculation of the system estimator write the moment conditions (6), (7), (8), (10), (11) and (12) compactly as

$$
E\left(\mathbf{Z}_{\mathbf{i}}^{\prime} \mathbf{U}_{\mathbf{i}}\right)=0
$$

where

$$
\mathbf{U}_{\mathbf{i}}=\left[\begin{array}{c}
\Delta \mathbf{u}_{\mathbf{i}} \\
\mathbf{u}_{\mathbf{i}}
\end{array}\right] \text { and } \mathbf{Z}_{\mathbf{i}}=\left(\begin{array}{cc}
\mathbf{Z}_{\mathrm{di}} & 0 \\
0 & \mathbf{Z}_{\mathrm{li}}
\end{array}\right)
$$

\footnotetext{
${ }^{13}$ Note that due to the presence of the moment condition (6) the moment conditions for $g>4$ would be redundant. Additionally the following moment conditions are valid in our situation: $E\left(u_{i 5} \Delta s_{i 5-g}\right)=0$ for $g=1,2,3$.

${ }^{14}$ Furthermore the additional moment conditions are valid for the ALMP measures: $E\left(u_{i 5} \Delta \Psi_{i 5-g}\right)=0$ for $g=1,2,3$.
} 
$\mathbf{Z}_{1 \mathbf{i}}$ is the matrix of instruments for the level equations and is defined in appendix C. The estimation is then analogous to the first-differenced GMM estimator. As weight matrix for the initial one-step estimates we follow Blundell, Bond, and Windmeijer (2000) and use:

$$
H_{i}=\left(\begin{array}{cc}
\mathbf{H}_{\mathbf{i}}^{\mathrm{D}} & 0 \\
0 & \mathbf{I}_{\mathbf{i}}
\end{array}\right),
$$

where $\mathbf{I}_{\mathbf{i}}$ is a $(T-4)$ identity matrix.

In contrast to the first-differenced GMM estimator, there is no one-step estimator that is asymptotically equivalent to the two-step estimator. The consistency of both GMM estimators relies heavily upon the fact that there is no serial correlation in the residuals. Arellano and Bond (1991) provide an asymptotic normal test statistic for first- and second-order serial correlation that is reported in our results. Furthermore Arellano and Bond (1991) note that since $\Delta v_{i t}$ is assumed to be the first difference of serial uncorrelated errors, the first-order serial correlation need not be zero for the first-differenced GMM estimator.

In order to test the set of instruments, a Sargan test of overidentifying restrictions is reported. This test is based on the minimised GMM criterion and is in the case of the first-differenced GMM estimator given by:

$$
J_{d}=\Delta \mathbf{u}\left(\beta_{\mathbf{2}}\right)^{\prime} \mathbf{Z} \mathbf{A}_{\mathbf{N}}\left(\beta_{\mathbf{1}}\right) \mathbf{Z}^{\prime} \Delta \mathbf{u}\left(\beta_{\mathbf{2}}\right),
$$

where $\beta_{2}$ relates to the two-step and $\beta_{1}$ to the one-step estimates. Under the null of instrument validity the Sargan test is asymptotically distributed as a chi-square with as many degrees of freedom as overidentifiying restrictions. ${ }^{15}$ In order to test the additional moment conditions of the system estimator, Blundell, Bond, and Windmeijer (2000) suggested to use the difference of the Sargan test for the system GMM estimator $J_{s}$ and the Sargan test for the first-differenced GMM estimator $J_{d}$. This test is then asymptotically distributed as chi-square distribution with $d f_{s}-d f_{d}$ degrees of freedom, where $d f_{s}$ and $d f_{d}$ are the degrees of freedom for the system and the first-differenced GMM estimator respectively.

A serious problem found in various Monte Carlo studies are the downward biased asymptotic standard errors of the two-step estimates. ${ }^{16}$ This is because the standard expression for the asymptotic variance ignores the presence of the estimated parameters in the weight matrix (Bond and Windmeijer, 2002). In order to overcome this problem, we apply the finite sample correction proposed by Windmeijer (2000). This finite sample correction accounts for the presence of the estimated parameter $\beta_{1}$ in the asymptotic variance of the two-step estimates:

$$
\boldsymbol{\Sigma}_{\left(\beta_{2}\right)}=\frac{1}{N}\left[\mathbf{C}^{\prime} \mathbf{A}_{\mathbf{n}}\left(\beta_{1}\right) \mathbf{C}\right]
$$

where $\mathbf{C}=\frac{\partial \mathbf{Z}^{\prime} \mathbf{u}\left(\beta_{2}\right)}{\partial \beta_{2}^{\prime}}$. The correction results from a first series Taylor expansion that generates an extra term as a function of the initial parameter estimates. ${ }^{17}$ Monte Carlo results have shown that the corrected variance of the two-step estimator often provides more reliable inference with

\footnotetext{
${ }^{15}$ Note that this statistic can also be calculated for the one-step estimates, even though they are not heteroscedasticity consistent.

${ }^{16}$ See for example Arellano and Bond (1991).

${ }^{17}$ See Windmeijer (2000) or Bond and Windmeijer (2002) for details.
} 
size proportions similar to those of the one-step variance (Bond and Windmeijer, 2002). For comparison we will present both the conventional and the corrected asymptotic variance in our results.

A final concern in our analysis regards the interpretation of the estimated parameters for the ALMP measures. Due to the specification with 4 lags for the ALMP measures, the interpretation of the results is not straightforward. Furthermore, a contemporary effect of ALMP that affects the contemporary job seeker rate has additionally an impact on the future job seeker rate due to the autoregressive specification. For these reasons we will calculate the lag coefficients for the ALMP measures. The lag coefficients enable us to observe the effect of an ALMP extension in e.g. $t-4$ on $s_{i t}$ directly. These direct effects can be obtained by rewriting (1) as:

$$
s_{i t}=\frac{a_{0}}{c(L)}+\sum_{j=1}^{3} \frac{a_{j}(L)}{c(L)} \psi_{i t}^{j}+\sum_{k=1}^{K} \frac{b_{k}(L)}{c(L)} x_{i t}^{k}+\frac{u_{i t}}{c(L)}
$$

The lag coefficients on the accommodation ratio $j$ are then the individual terms in the infinite lag polynomial $d_{j}(L)=d_{0}+d_{1} L+d_{2} L^{2} \cdots=\frac{a_{j}(L)}{c(L)}$. To find a solution for these lag coefficients one can use $d_{j}(L) c(L)=a_{j}(L)$ and equate the coefficients (Greene, 2000).

Since the lag coefficients are a nonlinear function of the terms in the polynomials $c(L)$ and $a_{j}(L)$, we use the delta method to calculate the standard errors. This method implies that the variance covariance matrix for the coefficients in $d_{j}(L)$ can be calculated from

$$
\boldsymbol{\Sigma}_{\left(\mathbf{d}_{\mathbf{j}}\right)}=\mathbf{G} \boldsymbol{\Sigma}_{(\mathbf{c}, \mathbf{a})} \mathbf{G}^{\prime}
$$

where $\mathbf{G}$ is a matrix of partial derivatives of the lag coefficients with respect to the estimated parameters and $\boldsymbol{\Sigma}_{\mathbf{c}, \mathbf{a}}$ is the covariance matrix for the estimated parameters (Greene, 2000).

The lag coefficients describe the impact on the change of the job seeker rate in $t+g$ originated from an ALMP extension in $t$. Additionally it would be interesting to consider the whole effect resulting from an ALMP extension, i.e. the total change of the job seeker rate after $g$ quarters. This effect can simply be calculated by the sum of the lag coefficients, $d_{0}+d_{1}+d_{2}+\cdots+d_{g}$. These cumulated lag coefficients enable us to assess the short- and medium-term effects on the job seeker rate resulting from an ALMP extension in $t$. In order to assess the consequences of ALMP in the long-run, we will also report the long-run effect that is simply given by the sum of the lag coefficients, $\sum_{i=0}^{\infty} d_{j, i}=\frac{a_{j}(1)}{c(1)}$ (Greene, 2000).

\subsection{Results}

Let us now turn to the results which are estimated separately for West and East Germany. To test the sensitivity of our results we present additionally to the first-differenced and the system GMM estimator the results from the OLS and the within estimator. ${ }^{18}$

The estimation of the effects of ALMP on the job seeker rate (JSR) in both regions is done with the same model with the exception, that for West Germany the structural adjustment schemes are not included. This is because the structural adjustment schemes are of minor importance in West Germany. Tables A.2 - A.3 in the appendix show that there are on average

\footnotetext{
${ }^{18}$ All estimations were done with the DPD98 programme for Gauss. See Arellano and Bond (1998).
} 
only 62 people in SAS programmes in West Germany, whereas in East Germany there are 3.105 participants on average. The other ALMP measures namely job creation schemes and vocational training are included for both regions. As stated above, all ALMP measures as well as the lagged job seeker rate are included with 4 lags. The national unemployment rate (NUR) and the national vacancy rate (NVR) are included with the first and the second lag. Both variables should account for the demand and supply situation on the national labour market which influences the situation on regional labour markets. Since there is also a causality between the regional labour market and the national labour market rate, both variables are included from the first lag on. ${ }^{19}$ Finally we have included seasonal dummies to control for the cyclic pattern in the quarterly data.

For West Germany we have restricted the number of moment conditions for both GMM estimators. This is advisable because the time dimension $T=12$ is relatively large compared to the number of cross sections $N=141$. Since the moment conditions (6) and (7) use the whole history (e.g. $s_{i t-2}, \cdots, s_{i 1}$ ) as instruments the number of overidentifying restrictions becomes rather large. As discussed in Bond (2002) and Arellano and Bond (1998) the inclusion of too many instruments may result in overfitting biases. To avoid this problem we do not use the whole history as instruments in the moment conditions (6) and (7). For the first-differenced GMM estimator we have truncated the history after $t-8$ and for the system GMM estimator we have truncated it after $t-6 .{ }^{20}$ Note that even if we use the reduced set of instruments for the system GMM estimator the number of moment conditions exceeds the number of cross sections. Due to the conventional specification of the moment conditions (e.g. see Blundell, Bond, and Windmeijer (2000)) the two-step weight matrix is estimated from only $N$ observations. In our case, where we instrument the variables that contain no regional information with themselves (i.e. these variables imply only $T$ additional observations), the weight matrix for the system GMM estimator is estimated with less observations than instruments anyway. ${ }^{21}$ Although the system estimator suffers from this problem there is no evidence of an overfitting bias, so the results for the system GMM estimator look most reliable. For East Germany this problem is more severe since we have only 34 observations at hand. Due to the reduced number of cross sections and the unchanged time dimension the GMM estimators are not very well suited. Therefore we will only present the results from the within and the OLS estimator.

Results for West Germany Table A.4 in the appendix reports the results of the OLS and within estimator for West Germany. In order to the test the specification, a Wald test of joint significance and a test for first- and second-order serial correlation is reported. ${ }^{22}$ For both equations the Wald test statistic leads to a rejection of the null hypothesis $\beta=0$ and the test for first-order serial correlation cannot reject the null, i.e. there is evidence for serial correlated errors. If we compare the coefficients for the ALMP measures, we find that there are no differences in the signs of the coefficients. Noteworthy is here that the OLS estimates imply

\footnotetext{
${ }^{19}$ Note that the national unemployment rate is determined by regional unemployment rates and thus cannot be strictly exogenous.

${ }^{20}$ The presence of the additional moment conditions for the level equations makes it advisable to truncate the history at an earlier point in time compared to the first-differenced GMM estimator.

${ }^{21} \mathrm{In}$ this case the weight matrix is calculated with a generalized inverse (see Arellano and Bond (1998) for details).

${ }^{22}$ See Arellano and Bond (1991) for the test on serial correlation.
} 
a much more persistent pattern of our model compared with the within estimator. Following Bond (2002) we measure the persistence of the autoregressive process by considering the sum of the estimated coefficients for the lagged depended variable, i.e. $c_{1}+c_{2}+c_{3}+c_{4}$. For the OLS estimator, the sum of the 4 coefficients on the job seeker rate is 0.96 whereas it is -0.008 for the within estimator. This coincides with the familiar result that the within estimator tends to be downward biased, whereas the OLS estimator tends to be upward biased.

Table 3 shows the two-step results from the first-differenced GMM estimator and the system estimator with the conventional and the corrected standard errors. The initial one-step results are reported in Table A.5 in the appendix. First, it is to note that the differences between the one and the two-step estimates are marginal and that we base our analysis for West Germany on the two-step estimates. For both GMM estimators we find that the Wald statistic rejects the null. The test for serial correlation rejects the null of second-order serial correlation for the firstdifferenced GMM estimator. ${ }^{23}$ For the system estimator there is no evidence of second-order serial correlation, and some of first-order serial correlation. The Sargan test of overidentifying restrictions cannot reject the set of instruments for both estimators. The difference between both Sargan tests is 8.2 with 66 degrees of freedom, i.e. the additional set of instruments cannot be rejected. Turning to the standard errors of the parameters, we observe a substantial difference between the conventional and the corrected standard errors. Particularly the conventional standard errors are much too small for both GMM estimators. Furthermore, since the corrected standard errors are similar to the one-step standard errors, there is a clear evidence that the conventional two-step standard errors are downward biased (see Windmeijer (2000)). This is clearly also the case for the Wald test, where the corrected statistic for the system GMM estimator amounts approximately 1 percent of the conventional statistic. ${ }^{24}$ Therefore we will base our inference on the corrected standard errors.

Turning to the coefficients on the ALMP measures, there is only one change in the signs that refers to the second lag of the JCS measure. Considering the dynamic pattern for both GMM estimators, the coefficients for the job seeker rate sum up to 0.02 for the first-differenced GMM and to 0.95 for the system GMM estimator.

Comparing the persistent pattern of all four estimators we find that the OLS estimator implies the most persistent pattern followed by the system GMM estimator, the first-differenced GMM and finally by the within estimator. Therefore we obtain a result that is similar to the findings of Blundell and Bond (1998) and Blundell, Bond, and Windmeijer (2000), where this sequence was found for simulated AR(1) processes. Furthermore the substantial difference between the first-differenced and the system GMM estimator indicates that the inclusion of the additional moment conditions for the level equations seems to be essential for the identification of the parameters. This may result from the highly persistent pattern of the job seeker rate or from a considerable variation between the regions.

As presented above we will analyse the lag coefficients of the ALMP measure in order to assess their impacts on the job seeker rate.

\footnotetext{
${ }^{23}$ Since the calculation of the second-order test statistics failed for the corrected standard errors we use the test statistic obtained from the conventional standard errors.

${ }^{24}$ See Bond and Windmeijer (2002) for Monte Carlo simulations.
} 
Table 3: Two Step DIF GMM and SYS GMM Estimation Results for West Germany $^{a}$

\begin{tabular}{|c|c|c|c|c|c|c|c|}
\hline Variable & & \multicolumn{3}{|c|}{$\begin{array}{l}\text { DIF GMM } \\
\text { Estimator }\end{array}$} & \multicolumn{3}{|c|}{$\begin{array}{l}\text { SYS GMM } \\
\text { Estimator }\end{array}$} \\
\hline \multirow{5}{*}{ Job Seeker Rate } & CONST. & - & - & - & 0.3240 & 28.836 & 5.550 \\
\hline & $J S R_{t-1}$ & 0.4618 & 102.695 & 5.307 & 0.8678 & 593.004 & 17.330 \\
\hline & $J S R_{t-2}$ & -0.2517 & -82.020 & -4.217 & -0.1059 & -42.118 & -1.391 \\
\hline & $J S R_{t-3}$ & -0.0159 & -9.519 & -0.541 & 0.1023 & 34.131 & 2.996 \\
\hline & $J S R_{t-4}$ & -0.1702 & -26.373 & -0.613 & 0.0931 & 38.334 & 0.796 \\
\hline Participants in Job & $J C S_{t}$ & -0.5682 & -65.020 & -5.301 & -0.8159 & -56.896 & -5.680 \\
\hline \multirow[t]{4}{*}{ Creation Schemes } & $J C S_{t-1}$ & 0.5786 & 43.974 & 4.984 & 0.8163 & 45.322 & 5.042 \\
\hline & $J C S_{t-2}$ & 0.1082 & 9.910 & 0.936 & -0.0120 & -0.974 & -0.131 \\
\hline & $J C S_{t-3}$ & 0.1277 & 16.783 & 1.545 & 0.0926 & 11.155 & 1.418 \\
\hline & $J C S_{t-4}$ & -0.1374 & -18.530 & -1.276 & -0.0800 & -13.120 & -1.217 \\
\hline Participants in & $V T_{t}$ & -0.2408 & -38.198 & -3.801 & -0.2035 & -29.440 & -4.874 \\
\hline \multirow[t]{4}{*}{ Vocational Training } & $V T_{t-1}$ & 0.1683 & 28.047 & 5.377 & 0.2226 & 30.271 & 6.084 \\
\hline & $V T_{t-2}$ & -0.0782 & -13.042 & -3.198 & -0.0681 & -13.644 & -3.105 \\
\hline & $V T_{t-3}$ & 0.0049 & 1.295 & 0.260 & 0.0265 & 4.632 & 1.232 \\
\hline & $V T_{t-4}$ & -0.0647 & -19.666 & -2.144 & -0.0394 & -9.766 & -1.814 \\
\hline National Unemployed & $N U R_{t-1}$ & -0.0475 & -0.614 & -0.055 & -2.1393 & -27.386 & -4.937 \\
\hline Rate & $N U R_{t-2}$ & 0.7782 & 12.827 & 1.319 & -0.2681 & -4.556 & -1.027 \\
\hline National Vacancies & $N V R_{t-1}$ & 3.0178 & 15.320 & 0.863 & -1.7298 & -10.885 & -1.295 \\
\hline Rate & $N V R_{t-2}$ & -3.4925 & -11.302 & -3.094 & -5.7844 & -20.191 & -3.741 \\
\hline Seasonal Dummy 1 & $S D_{1}$ & 0.0045 & 9.460 & 0.648 & -0.0099 & -22.964 & -5.140 \\
\hline Seasonal Dummy 2 & $S D_{2}$ & -0.0087 & -10.050 & -1.042 & 0.0005 & 0.510 & 0.065 \\
\hline Seasonal Dummy 3 & $S D_{3}$ & -0.0142 & -28.872 & -1.397 & -0.0017 & -5.211 & -0.546 \\
\hline \multicolumn{2}{|c|}{ Wald test of joint significance } & $(21)$ & 1004452.75 & 3617.29 & $(21)$ & 4089865.48 & 39629.64 \\
\hline \multicolumn{2}{|c|}{ Sargan test } & $(115)$ & 124.06 & 124.06 & $(181)$ & 132.25 & 132.25 \\
\hline \multicolumn{2}{|c|}{ First-order serial correlation } & $(141)$ & -2.41 & -2.23 & $(141)$ & -2.09 & -2.12 \\
\hline \multicolumn{2}{|c|}{ Second-order serial correlation } & $(141)$ & -0.74 & - & $(141)$ & 0.06 & - \\
\hline \multicolumn{2}{|c|}{ No. of observations $(N, T)$} & & & 141,12 & & & 141,12 \\
\hline
\end{tabular}

${ }^{a}$ Degrees of freedom for the test statistics are in parenthesis.

DIF GMM is the first-differenced GMM estimator.

SYS GMM is the system GMM estimator.

${ }^{b}$ Corrected standard errors as suggested by Windmeijer (2000). 
Figure 1: Cumulated Lag Coefficients for Job Creation Schemes in West Germany ${ }^{a}$
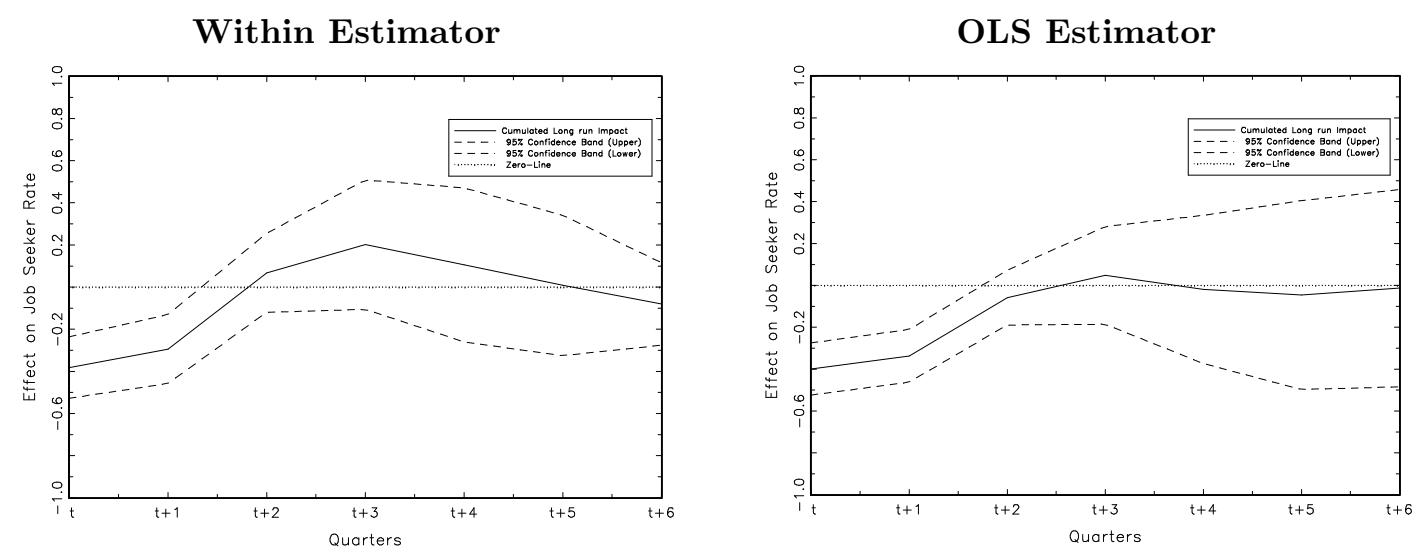

DIF GMM Estimator

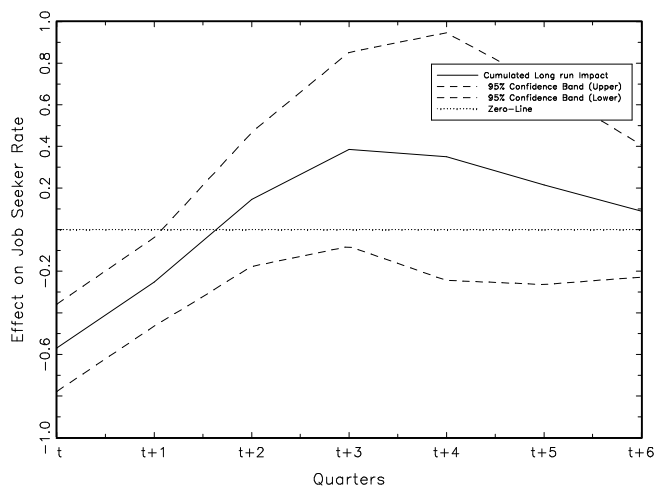

SYS GMM Estimator

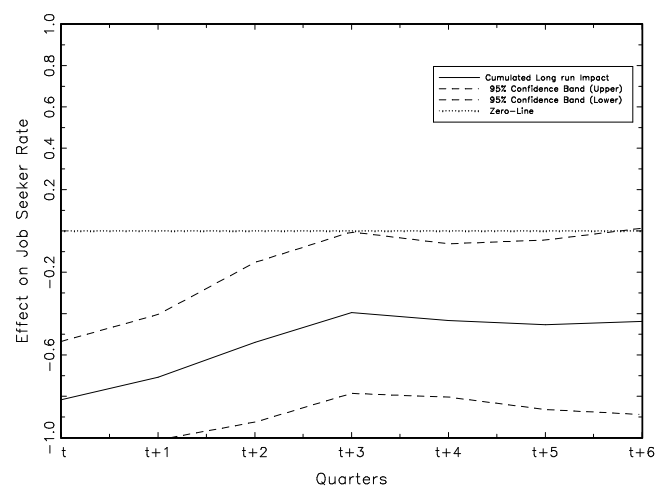

${ }^{a}$ DIF GMM and SYS GMM cumulated lag coefficients result from two-step estimates with corrected standard errors; Standard errors for OLS and within are asymptotically robust to heteroscedasticity. 
Figure 2: Cumulated Lag Coefficients for Vocational Training in West Germany ${ }^{a}$
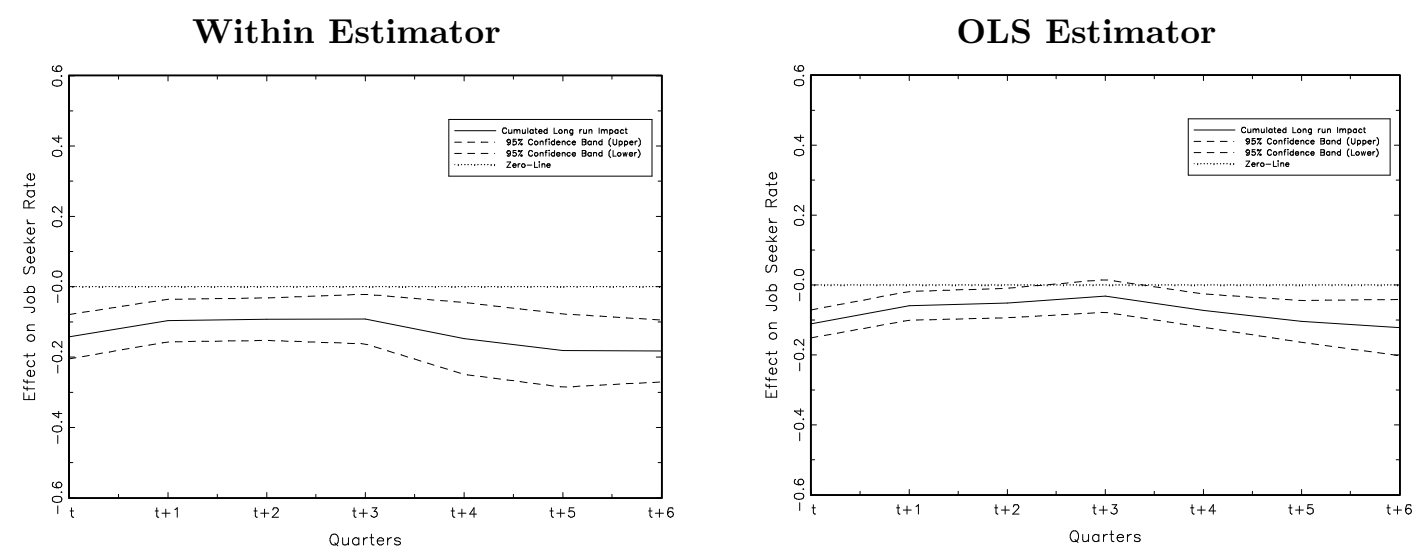

DIF GMM Estimator

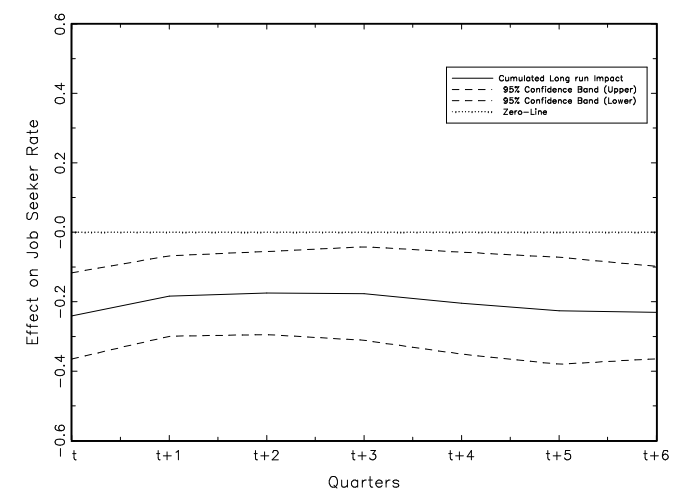

SYS GMM Estimator

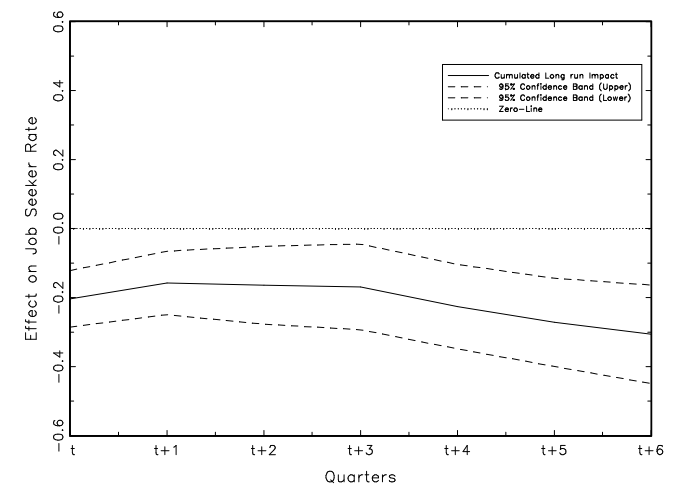

${ }^{a}$ DIF GMM and SYS GMM cumulated lag coefficients result from two-step estimates with corrected standard errors; Standard errors for OLS and within are asymptotically robust to heteroscedasticity. 
We choose to calculate the lag coefficients up to $t+6$ quarters and to summarize the effects beyond this timeframe with the long-run effect. The lag coefficients and the long-run effect for both measures are reported in table A.6. Furthermore the cumulated lag coefficients are plotted in figure 1 for job creation schemes and in figure 2 for vocational training programmes.

For job creation schemes it can be seen that the cumulated lag coefficients resulting from the OLS, the within and the first-differenced GMM estimator are quite similar. For all these estimators we find a significant negative effect at the beginning that vanishes after the first quarter. Only the system estimates bear evidence of a significant negative effect until $t+6$. Looking at the long-run effects, we do not find any significant effect for the job creation schemes. Therefore we conclude that the job creation schemes in West Germany only are able to reduce the job seeker rate in the short-run.

Turning to vocational training programmes we find a quite different pattern. For the firstdifferenced and the system GMM estimator as well as for the within estimator we find throughout a significant negative effect. Only for the OLS estimator the effect is at $t+3$ not significant. The long-run effects are for all estimators negative significant. Hence we conclude that the vocational training programmes in West Germany have a throughout negative effect on the job seeker rate. Furthermore the cumulated lag coefficients resulting from the system estimator decline after $t+3$. This stronger negative effect on the job seeker rate can possible be explained by a locking in effect as described in section 3.

Results for East Germany The results for the OLS and the within estimator are presented in Table 4. Similar to West Germany, the Wald test rejects the null and there is evidence of first-order serial correlation. One important thing to note is that the OLS estimator implies an unstable path for the job seeker rate. Therefore the within estimator seems to be the most reliable estimator for East Germany although the finite sample bias with $T=12$ should not be negligible. In order to assess the effects of the ALMP measures, we will again analyse the cumulated lag coefficients. The lag coefficients resulting from the OLS and the within estimator can be found in Table A.7 in the appendix. Figure 3 shows the cumulated lag coefficients for job creation schemes, structural adjustment schemes and vocational training programmes for East Germany. For the job creation schemes we do not find any significant effect on the job seeker rate. The long-run effects are always insignificant, too. Since this result holds for the within and the OLS estimator we may see this as an evidence that the job creation schemes have no effect on the job seeker rate in East Germany. Considering the structural adjustment schemes, we find a significant effect that appears after 4 quarters. This pattern is observed for both estimators, whereas the effect remains weakly significant in the long-run for the within estimator. Finally we find that for vocational training programmes there are major differences between the OLS and the within estimator. In particular we find for the within estimator an insignificant positive effect that remains insignificant in the long-run. In contrast, the results from the OLS estimator indicate a negative effect after the second quarter. But since the OLS estimates determine an explosive path for the job seeker rate (what should be seen as an evidence that the OLS estimates of the autoregressive parameters are upward biased) the result is not reliable. Furthermore, since the within estimator is also biased, a profound statement about the effects of vocational training in East Germany cannot be made. 
Table 4: OLS and Within Estimation Results for East Germany ${ }^{a}$

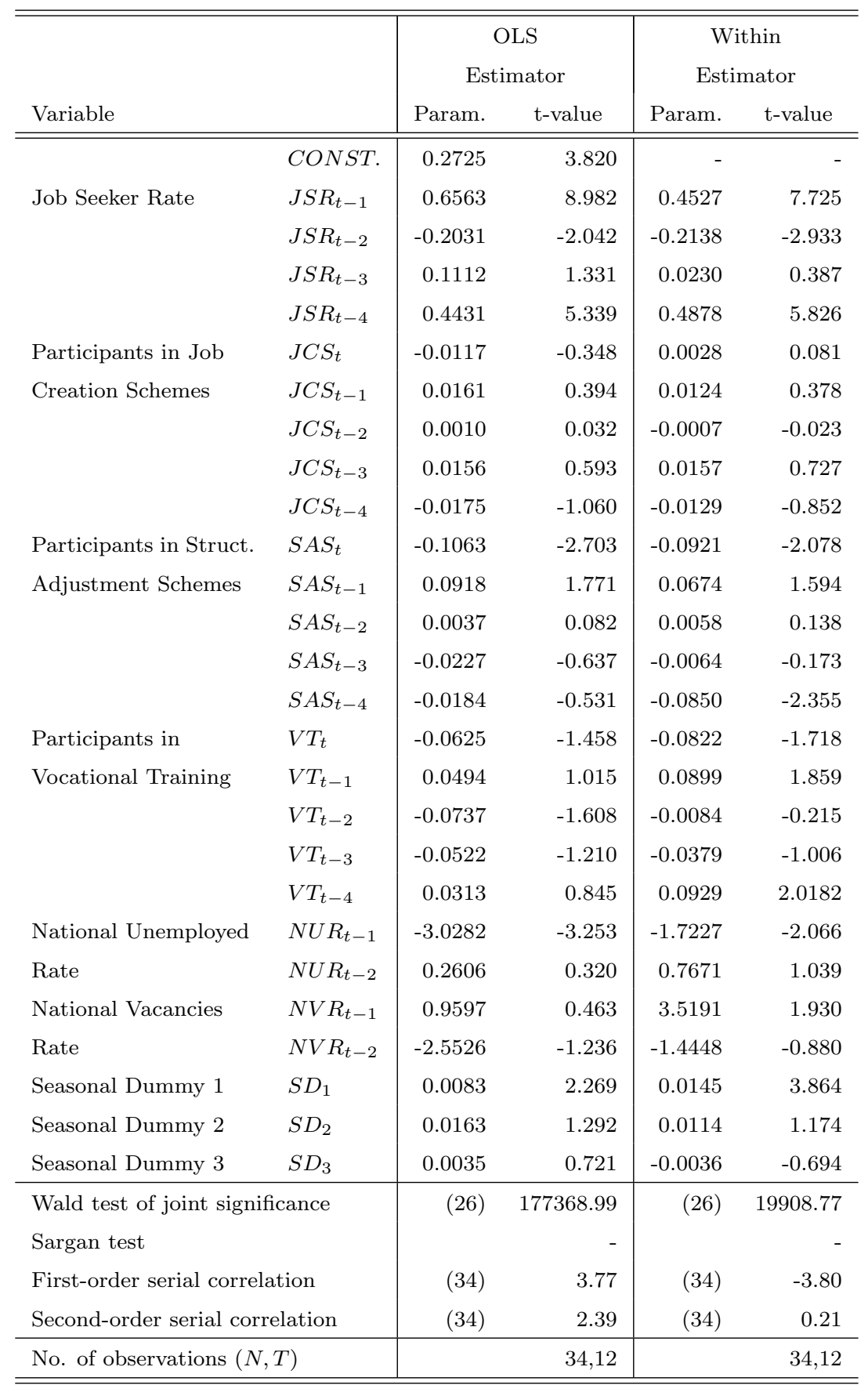

${ }^{a}$ Degrees of freedom for the test statistics are in parenthesis.

Asymptotic standard errors and test statistics are asymptotically robust to heteroscedasticity. 
Figure 3: Cumulated Lag Coefficients East Germany ${ }^{a}$

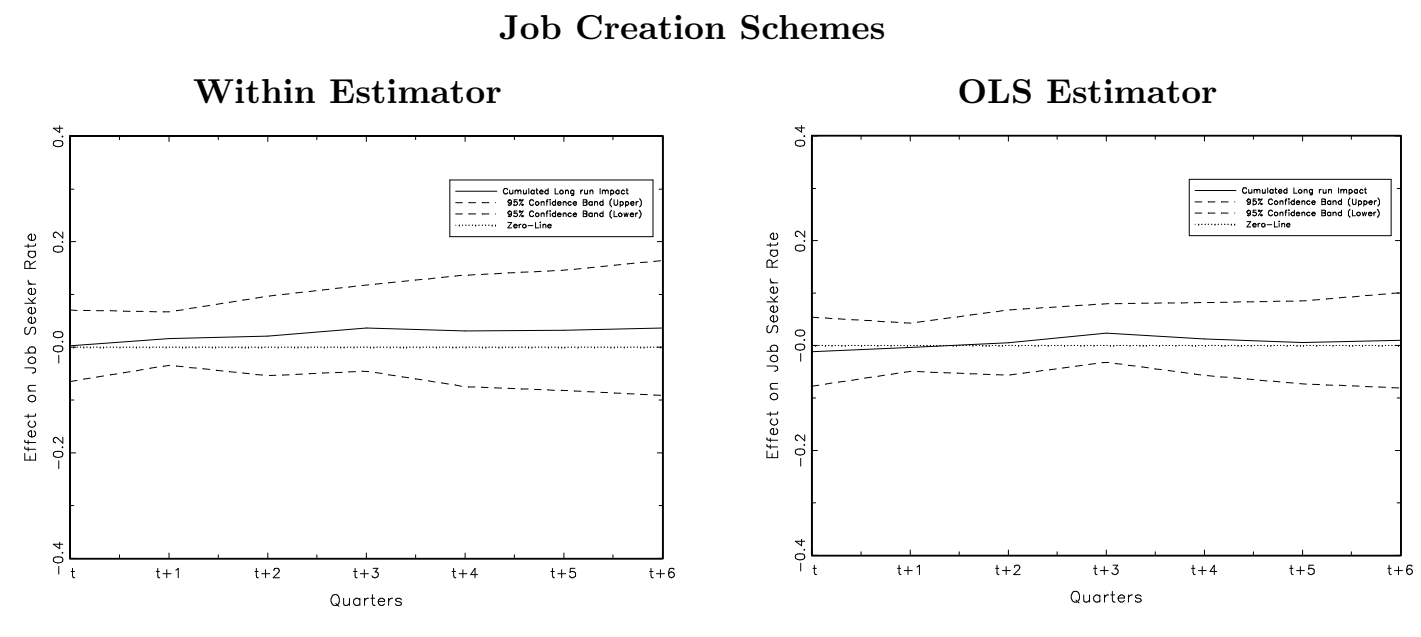

Structural Adjustment Schemes
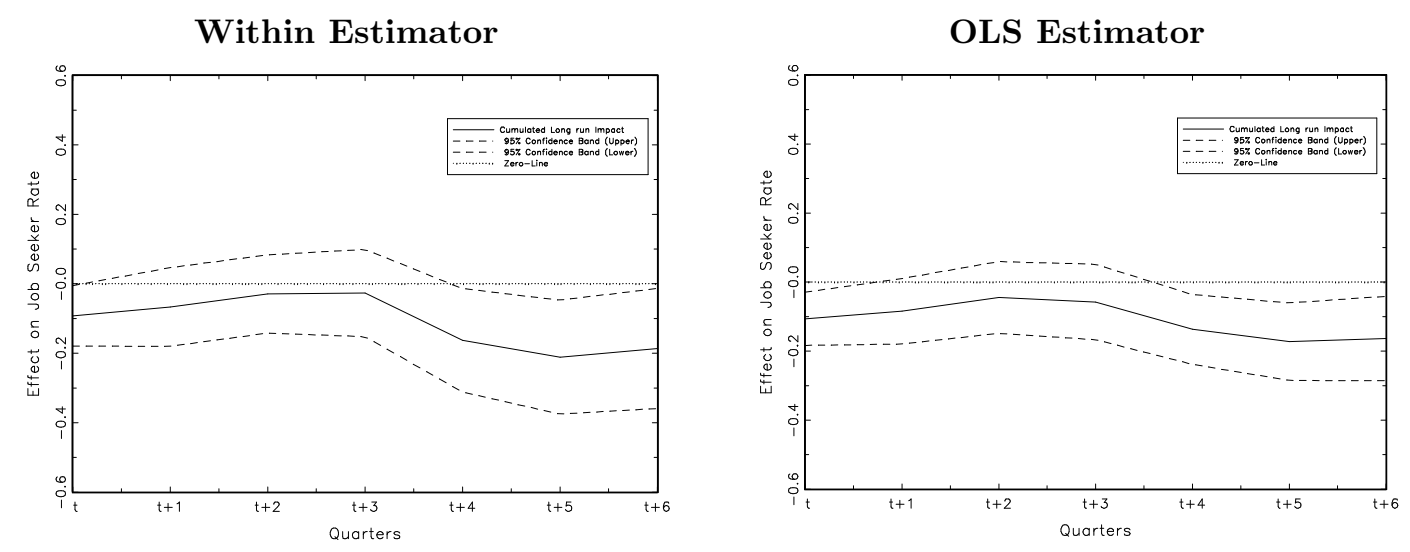

Vocational Training
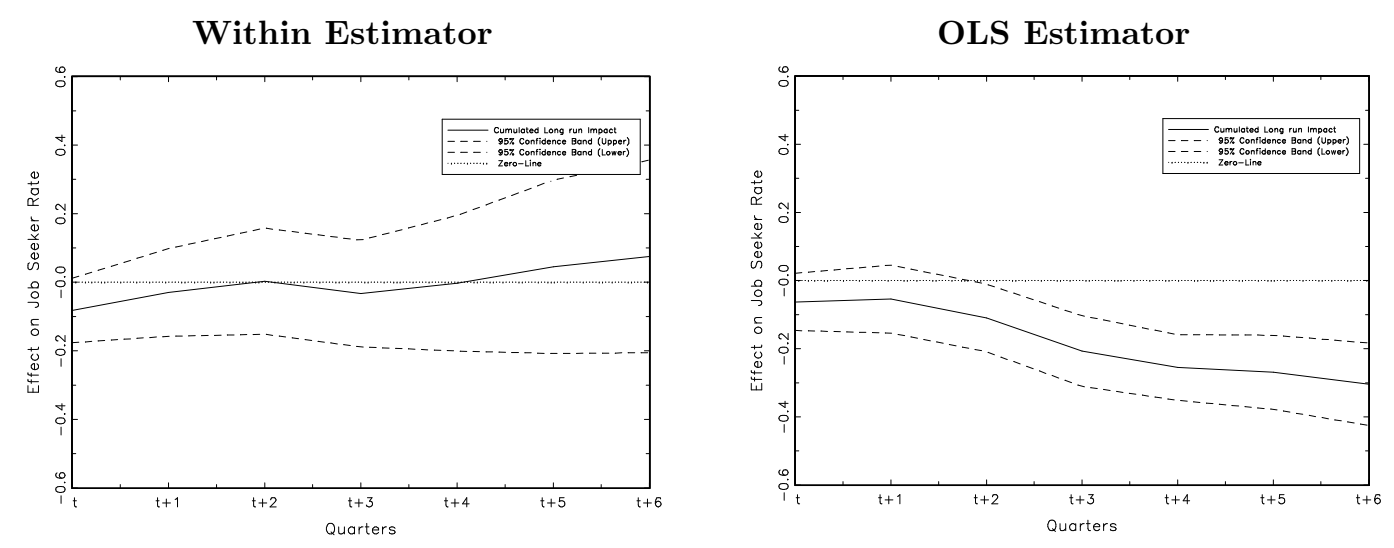

${ }^{a}$ Asymptotic standard errors are asymptotically robust to heteroscedasticity. 


\section{Conclusion}

We were interested in estimating the net effects of ALMP in Germany. As microeconometric evaluations usually ignore impacts on the non-participants, we used a macroeconometric approach to analyse the effects of job creation schemes, structural adjustment schemes and vocational training on the employment situation in Germany for the time span from 1999 to 2001.

As a starting point of our analysis, we discussed various channels through which ALMP might influence the whole economy in a theoretical framework. Following that, we stressed the importance of suitable data for evaluation purposes which allow to take regional heterogeneity into account. This matters especially for the time period under consideration because the introduction of the New Social Code SGB III in 1998 decentralized the institutional organization of labour market policy in Germany, allowing more flexibility in the regional allocation of resources to different measures. Due to this fact, any evaluation has to give more consideration to regional aspects than before. To do so we used a regional data set for 175 labour office districts in West and East Germany. The availability of quarterly data allowed us to take dynamics and persistency on the labour market into account. The fact that there are major differences between the East and the West German labour markets made a separate estimation for both areas necessary. We based our empirical specification on a reduced form relationship to evaluate the impact of ALMP on the total rate of job seekers, i.e. the openly unemployed and the programme participants. To control for the problems arising from a dynamic panel data model, we applied the GMM estimation procedures suggested by Arellano and Bond (1991) and Blundell and Bond (1998). Furthermore we used the two-step standard error correction proposed by Windmeijer (2000) to make reliable inference about the two-step estimates. Within those methods for dynamic panel data models we also accounted for the inherent simultaneity problem of ALMP.

Our results indicate for West Germany that vocational training has a negative significant effect, that is vocational training is able to reduce the job seeker rate. For job creation schemes we find negative effects only in the short-term that become insignificant in the long-term.

As there were only a small number of regional units at hand the results for East Germany should be handled with care. In this situation the within estimator seems to be the most reliable one. For job creation schemes we do not find any evidence of a significant effect, whereas for structural adjustment schemes there is a weak evidence for a negative effect in the medium-term. For vocational training different results from different estimators indicate that the reliability of the results is very questionable.

A major task for future work is to analyse the several effects of ALMP with a structural model. Since a reduced form approach can only measure the net effect of ALMP, the different channels through which ALMP might effect the economy cannot be detected. The major problem here is the lack of suitable data that would allow to consider the effects of ALMP on the matching efficiency or on the wages. Basically, the ideal macroeconomic evaluation requires three things: First of all, a well developed macroeconomic theory which is, secondly, applicable in an econometric framework and finally does not fail due to data limitations. 
A Tables

Table A.1: Descriptive Statistics for Germany

\begin{tabular}{|c|c|c|c|c|}
\hline Variable & Mean & Std & Min & $\operatorname{Max}$ \\
\hline \multicolumn{5}{|c|}{ Number of labour office districts: 175} \\
\hline \multicolumn{5}{|l|}{ No. of observations: 2100} \\
\hline \multicolumn{5}{|c|}{ Time Range: 1999:1 - 2001:4 } \\
\hline \multicolumn{5}{|c|}{ Quarterly Average Measures } \\
\hline Participants in JCS & 1041 & 1682 & 3 & 12547 \\
\hline Participants in SAS & 653 & 1468 & 0 & 9091 \\
\hline Participants in VT & 1890 & 1407 & 255 & 8500 \\
\hline Unemployment & 20855 & 14108 & 3331 & 88317 \\
\hline Dependent Labour Force & 200124 & 112471 & 54113 & 991637 \\
\hline \multicolumn{5}{|l|}{ Regional Information } \\
\hline Area (in hectare) & 203502 & 134599 & 16406 & 813574 \\
\hline \multicolumn{5}{|l|}{ Additional National Data } \\
\hline National Unemployed & 3943250 & 206213 & 3688358 & 4402852 \\
\hline National Vacancies & 492768 & 49220 & 413141 & 562266 \\
\hline National Labour Force & 41668 & 281 & 41116 & 42068 \\
\hline
\end{tabular}


Table A.2: Descriptive Statistics for West Germany

\begin{tabular}{l|llll}
\hline \hline Variable & Mean & Std & Min & Max \\
\hline \hline
\end{tabular}

Number of labour office districs: 141

No. of observations: 1692

Time Range: 1999:1 - 2001:4

\begin{tabular}{l|rrrr}
\hline \hline Quarterly Average Measures & 356 & 339 & 3 & 2181 \\
\hline Participants in JCS & 62 & 107 & 0 & 1241 \\
Participants in SAS & 1227 & 930 & 255 & 8500 \\
Participants in VT & 17092 & 11282 & 3331 & 88317 \\
Unemployed & 201539 & 119919 & 59864 & 991637 \\
Dependent Labour Force & & & & \\
\hline \hline Regional Information & 176204 & 95609 & 16406 & 478275 \\
\hline Area (in hectare)
\end{tabular}

Table A.3: Descriptive Statistics for East Germany

\begin{tabular}{l|rrrr}
\hline \hline Variable & Mean & Std & Min & Max \\
\hline \hline Number of labour office districs: 34 & & & & \\
No. of observations: 408 & & & & \\
Time Range: 1999:1 - 2001:4 & & & & \\
\hline \hline Quarterly Average Measures & 3882 & 2019 & 1048 & 12547 \\
\hline Participants in JCS & 3105 & 1894 & 514 & 9091 \\
Participants in SAS & 3813 & 1422 & 1139 & 8197 \\
Participants in VT & 36462 & 13946 & 10671 & 74296 \\
Unemployment & 194258 & 73800 & 54113 & 368984 \\
Dependent Labour Force & 316708 & 198754 & 56906 & 813574 \\
\hline \hline Regional Information & & & & \\
\hline Area (in hectare)
\end{tabular}


Table A.4: OLS and Within Estimation Results for West Germany ${ }^{a}$

\begin{tabular}{|c|c|c|c|c|c|}
\hline \multirow[b]{2}{*}{ Variable } & & \multicolumn{2}{|c|}{$\begin{array}{c}\text { OLS } \\
\text { Estimator }\end{array}$} & \multicolumn{2}{|c|}{$\begin{array}{c}\text { Within } \\
\text { Estimator }\end{array}$} \\
\hline & & Param. & $\mathrm{t}$-value & Param. & t-value \\
\hline & CONST. & 0.2774 & 6.544 & - & - \\
\hline \multirow[t]{4}{*}{ Job Seeker Rate } & $J S R_{t-1}$ & 0.8514 & 15.026 & 0.4577 & 5.394 \\
\hline & $J S R_{t-2}$ & -0.1324 & -1.734 & -0.2736 & -4.445 \\
\hline & $J S R_{t-3}$ & 0.1310 & 4.156 & 0.0025 & 0.860 \\
\hline & $J S R_{t-4}$ & 0.1182 & 0.952 & -0.1948 & -0.632 \\
\hline Participants in Job & $J C S_{t}$ & -0.3992 & -6.294 & -0.3818 & -5.131 \\
\hline \multirow[t]{4}{*}{ Creation Schemes } & $J C S_{t-1}$ & 0.4024 & 3.991 & 0.2623 & 3.709 \\
\hline & $J C S_{t-2}$ & 0.1723 & 1.947 & 0.2172 & 1.694 \\
\hline & $J C S_{t-3}$ & -0.0706 & -1.509 & -0.0063 & -0.107 \\
\hline & $J C S_{t-4}$ & -0.0809 & -1.346 & -0.1336 & -1.221 \\
\hline Participants in & $V T_{t}$ & -0.1111 & -5.420 & -0.1418 & -4.408 \\
\hline \multirow[t]{4}{*}{ Vocational Training } & $V T_{t-1}$ & 0.1465 & 5.365 & 0.1107 & 6.045 \\
\hline & $V T_{t-2}$ & -0.0509 & -2.997 & -0.0559 & -2.510 \\
\hline & $V T_{t-3}$ & 0.0349 & 2.344 & 0.0116 & 0.839 \\
\hline & $V T_{t-4}$ & -0.0516 & -2.216 & -0.0821 & -2.841 \\
\hline National Unemployed & $N U R_{t-1}$ & -2.0823 & -4.931 & -0.0575 & -0.067 \\
\hline Rate & $N U R_{t-2}$ & -0.0787 & -0.390 & 1.2318 & -3.595 \\
\hline National Vacancies & $N V R_{t-1}$ & -3.2884 & -2.563 & 1.8873 & 0.542 \\
\hline Rate & $N V R_{t-2}$ & -2.7993 & -2.273 & -0.6821 & -0.842 \\
\hline Seasonal Dummy 1 & $S D_{1}$ & -0.0095 & -6.465 & 0.0057 & 0.764 \\
\hline Seasonal Dummy 2 & $S D_{2}$ & 0.0071 & 0.968 & -0.0015 & -0.201 \\
\hline Seasonal Dummy 3 & $S D_{3}$ & 0.0020 & 0.725 & -0.0133 & -1.203 \\
\hline \multicolumn{2}{|c|}{ Wald test of joint significance } & $(21)$ & 143600.99 & $(21)$ & 7431.45 \\
\hline \multicolumn{2}{|l|}{ Sargan test } & & - & & - \\
\hline \multicolumn{2}{|c|}{ First-order serial correlation } & $(141)$ & 3.18 & $(141)$ & -3.85 \\
\hline \multicolumn{2}{|c|}{ Second-order serial correlation } & $(141)$ & 1.90 & $(141)$ & -0.00 \\
\hline \multicolumn{2}{|c|}{ No. of observations $(N, T)$} & & 141,12 & & 141,12 \\
\hline
\end{tabular}

${ }^{a}$ Degrees of freedom for the test statistics are in parenthesis.

Asymptotic standard errors and test statistics are asymptotically robust to heteroscedasticity. 
Table A.5: One Step DIF and SYS Estimation Results for West Germany ${ }^{a}$

\begin{tabular}{|c|c|c|c|c|c|}
\hline \multirow[b]{2}{*}{ Variable } & & \multicolumn{2}{|c|}{$\begin{array}{l}\text { DIF GMM } \\
\text { Estimator }\end{array}$} & \multicolumn{2}{|c|}{$\begin{array}{l}\text { SYS GMM } \\
\text { Estimator }\end{array}$} \\
\hline & & Param. & t-value & Param. & t-value \\
\hline \multirow{5}{*}{ Job Seeker Rate } & CONST. & - & - & 0.3252 & 6.562 \\
\hline & $J S R_{t-1}$ & 0.4531 & 5.243 & 0.8673 & 16.972 \\
\hline & $J S R_{t-2}$ & -0.2460 & -3.993 & -0.1070 & -1.437 \\
\hline & $J S R_{t-3}$ & -0.0150 & -0.527 & 0.1029 & 3.148 \\
\hline & $J S R_{t-4}$ & -0.1869 & -0.673 & 0.0934 & 0.793 \\
\hline Participants in Job & $J C S_{t}$ & -0.5722 & -5.723 & -0.7995 & -5.733 \\
\hline \multirow[t]{4}{*}{ Creation Schemes } & $J C S_{t-1}$ & 0.5646 & 5.056 & 0.7956 & 5.086 \\
\hline & $J C S_{t-2}$ & 0.1176 & 0.125 & -0.0057 & -0.063 \\
\hline & $J C S_{t-3}$ & 0.1315 & 1.721 & 0.0861 & 1.355 \\
\hline & $J C S_{t-4}$ & -0.1388 & -1.318 & -0.0782 & -1.275 \\
\hline Participants in & $V T_{t}$ & -0.2456 & -3.774 & -0.2054 & -5.285 \\
\hline \multirow[t]{4}{*}{ Vocational Training } & $V T_{t-1}$ & 0.1679 & 5.127 & 0.2232 & 6.220 \\
\hline & $V T_{t-2}$ & -0.0769 & -3.760 & -0.0676 & -3.466 \\
\hline & $V T_{t-3}$ & 0.0053 & 0.312 & 0.0256 & 1.395 \\
\hline & $V T_{t-4}$ & -0.0690 & -2.388 & -0.0397 & -1.644 \\
\hline National Unemployed & $N U R_{t-1}$ & -0.0640 & -0.077 & -2.1747 & -4.839 \\
\hline Rate & $N U R_{t-2}$ & 0.8247 & 1.443 & -0.2378 & -0.927 \\
\hline National Vacancies & $N V R_{t-1}$ & 3.1582 & 0.872 & -1.7876 & -1.329 \\
\hline Rate & $N V R_{t-2}$ & -3.5434 & -2.959 & -5.7617 & -3.762 \\
\hline Seasonal Dummy 1 & $S D_{1}$ & 0.0048 & 0.692 & -0.0100 & -5.913 \\
\hline Seasonal Dummy 2 & $S D_{2}$ & -0.0087 & -0.987 & 0.0008 & 0.104 \\
\hline Seasonal Dummy 3 & $S D_{3}$ & -0.0104 & -1.426 & -0.0018 & -0.649 \\
\hline \multicolumn{2}{|c|}{ Wald test of joint significance } & $(21)$ & 3767.18 & $(21)$ & 47579.13 \\
\hline \multicolumn{2}{|l|}{ Sargan test } & & - & & - \\
\hline \multicolumn{2}{|c|}{ First-order serial correlation } & $(141)$ & -3.84 & $(141)$ & -2.25 \\
\hline \multicolumn{2}{|c|}{ Second-order serial correlation } & $(141)$ & -0.60 & $(141)$ & 0.09 \\
\hline \multicolumn{2}{|c|}{ No. of observations $(N, T)$} & & 141,12 & & 141,12 \\
\hline
\end{tabular}

${ }^{a}$ Degrees of freedom for the test statistics are in parenthesis.

Asymptotic standard errors and test statistics are asymptotically robust to heteroscedasticity.

DIF GMM is the first-differenced GMM estimator.

SYS GMM is the system GMM estimator. 
Table A.6: Lag Coefficients for West Germany

\begin{tabular}{|c|c|c|c|c|c|c|c|c|c|}
\hline \multirow{2}{*}{\multicolumn{2}{|c|}{ Programme }} & \multicolumn{4}{|c|}{ OLS Estimator } & \multicolumn{4}{|c|}{ Within Estimator } \\
\hline & & \multirow{2}{*}{$\begin{array}{c}\text { lag } \\
\text { coeff. } \\
-0.3992\end{array}$} & \multirow{2}{*}{$\begin{array}{c}\text { s.e. } \\
0.0634\end{array}$} & \multirow{2}{*}{$\begin{array}{c}\text { cum. } \\
\text { lag coeff. } \\
-0.3992\end{array}$} & \multirow{2}{*}{$\begin{array}{c}\text { s.e. } \\
0.0634\end{array}$} & \multirow{2}{*}{$\begin{array}{c}\text { lag } \\
\text { coeff. }\end{array}$} & \multirow{2}{*}{$\begin{array}{c}\text { s.e. } \\
0.0744\end{array}$} & \multirow{2}{*}{$\begin{array}{c}\begin{array}{c}\text { cum. } \\
\text { lag coeff. }\end{array} \\
-0.3818\end{array}$} & \multirow{2}{*}{$\begin{array}{c}\text { s.e. } \\
0.0744\end{array}$} \\
\hline JCS & $t$ & & & & & & & & \\
\hline & $t+1$ & 0.0625 & 0.0526 & -0.3367 & 0.0642 & 0.0876 & 0.0551 & -0.2943 & 0.0836 \\
\hline & $t+2$ & 0.2783 & 0.0567 & -0.0584 & 0.0666 & 0.3617 & 0.1061 & 0.0675 & 0.0955 \\
\hline & $t+3$ & 0.1059 & 0.0786 & 0.0475 & 0.1190 & 0.1343 & 0.0746 & 0.2018 & 0.1567 \\
\hline & $t+4$ & -0.0666 & 0.0762 & -0.0191 & 0.1805 & -0.0966 & 0.0488 & 0.1052 & 0.1863 \\
\hline & $t+5$ & -0.0269 & 0.0539 & -0.0460 & 0.2230 & -0.0971 & 0.0325 & 0.0081 & 0.1701 \\
\hline & $t+6$ & 0.0327 & 0.0138 & -0.0134 & 0.2405 & -0.0881 & 0.1475 & -0.0800 & 0.0999 \\
\hline & long run & - & - & 0.7551 & 1.1141 & - & - & -0.0420 & 0.0894 \\
\hline \multirow[t]{8}{*}{ VT } & $t$ & -0.1112 & 0.0205 & -0.1112 & 0.0205 & -0.1418 & 0.0322 & -0.1418 & 0.0322 \\
\hline & $t+1$ & 0.0518 & 0.0125 & -0.0593 & 0.0209 & 0.0457 & 0.0167 & -0.0961 & 0.0309 \\
\hline & $t+2$ & 0.0079 & 0.0141 & -0.0515 & 0.0214 & 0.0039 & 0.0227 & -0.0922 & 0.0308 \\
\hline & $t+3$ & 0.0202 & 0.0123 & -0.0312 & 0.0239 & 0.0005 & 0.0155 & -0.0917 & 0.0360 \\
\hline & $t+4$ & -0.0418 & 0.0085 & -0.0730 & 0.0244 & -0.0551 & 0.0295 & -0.1469 & 0.0520 \\
\hline & $t+5$ & -0.0311 & 0.0124 & -0.1041 & 0.0304 & -0.0343 & 0.0074 & -0.1811 & 0.0531 \\
\hline & $t+6$ & -0.0174 & 0.0137 & -0.1214 & 0.0410 & -0.0013 & 0.0125 & -0.1825 & 0.0449 \\
\hline & long run & - & - & -1.0171 & 0.2365 & - & - & -0.1562 & 0.0458 \\
\hline
\end{tabular}

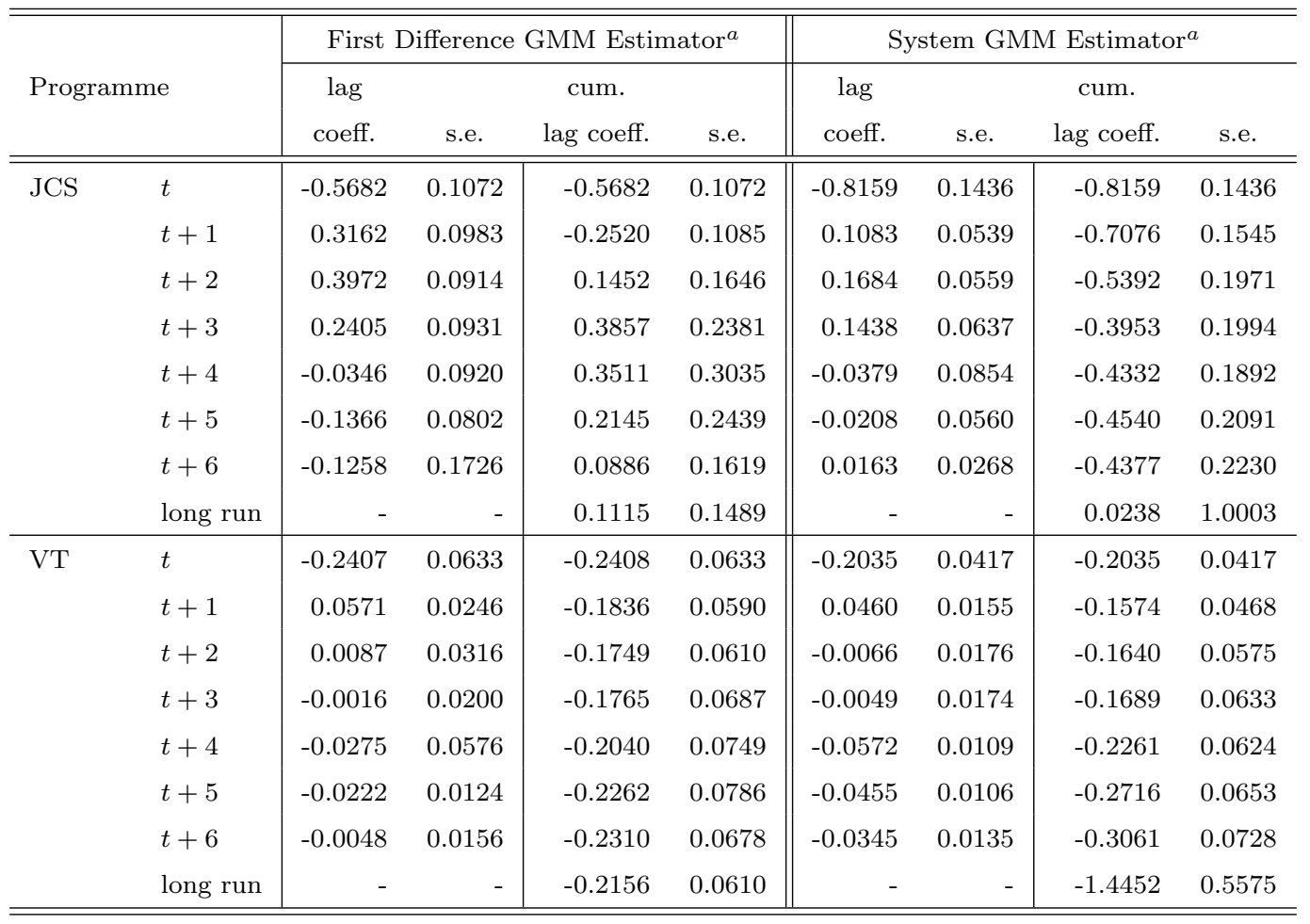

${ }^{a}$ Two step estimates with corrected standard errors. 
Table A.7: Lag Coefficients for East Germany

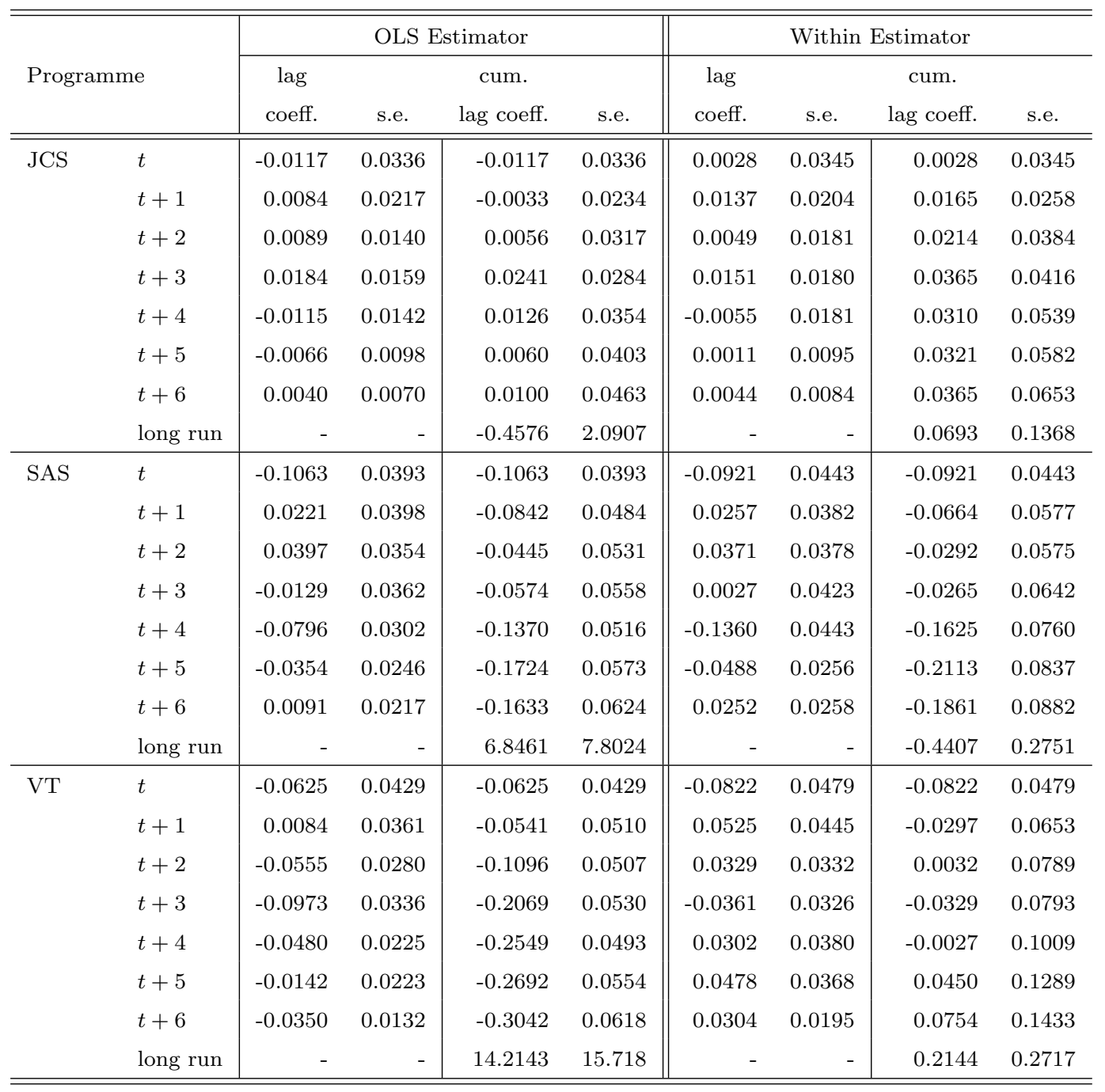




\section{B Figures}

Figure B.1: Participants in ALMP and Unemployed in West Germany, 04/98-04/01

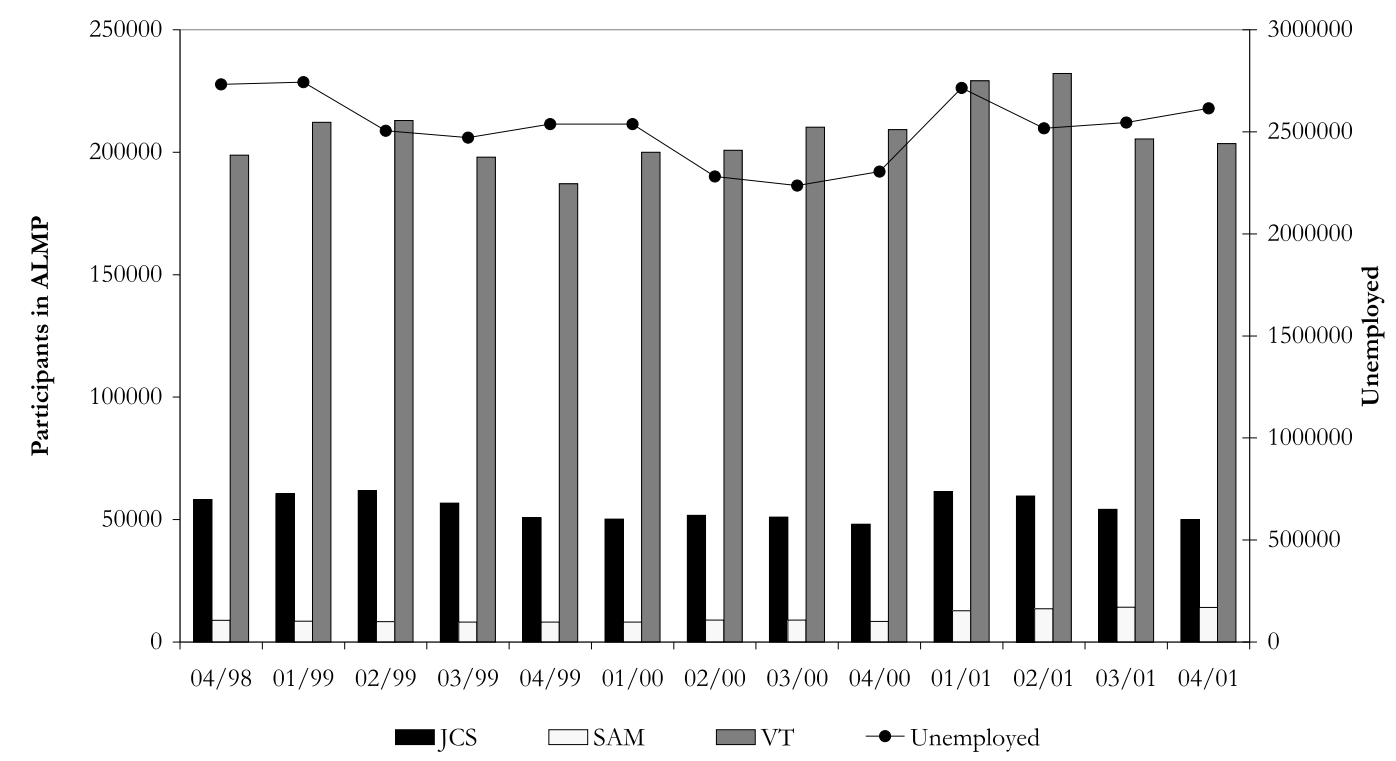

Figure B.2: Participants in ALMP and Unemployed in East Germany, 04/98-04/01

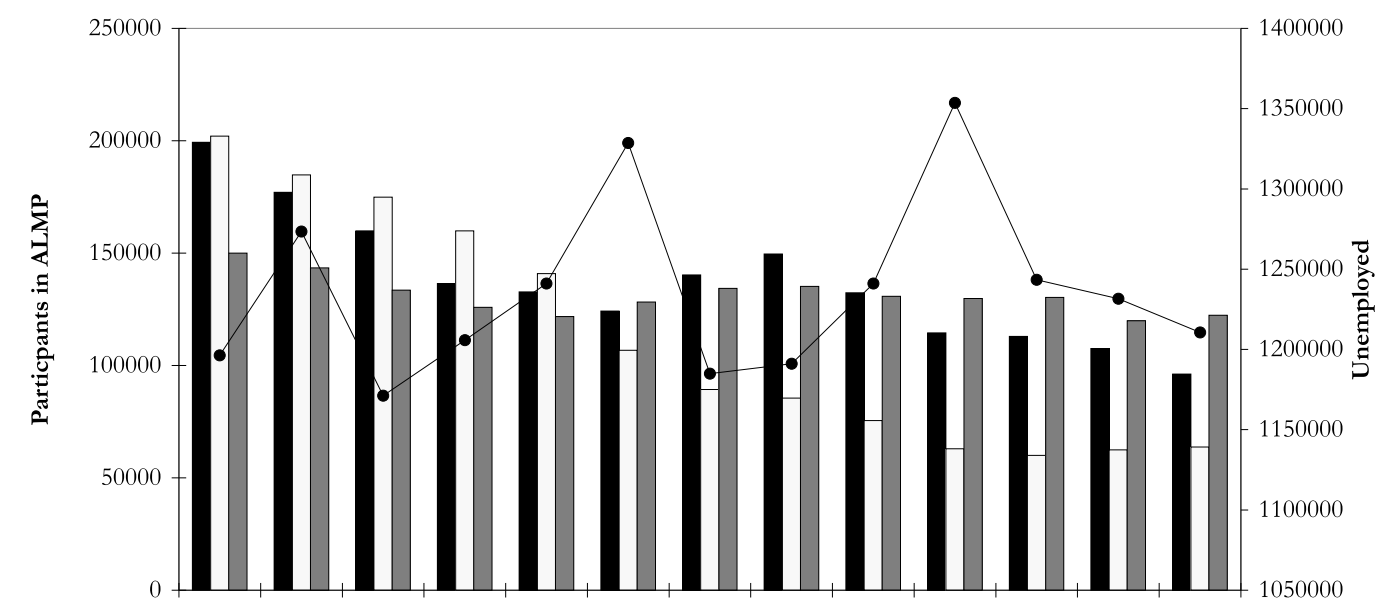

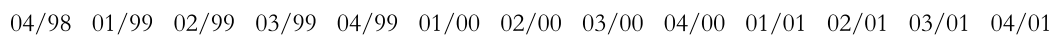

$\square \mathrm{JCS} \quad \square \mathrm{SAM} \quad \square \mathrm{VT} \quad \bullet$ Unemployed 
Figure B.3: Job Seeker Rate in Germany (Monthly Average), 1999 ${ }^{(a)}$

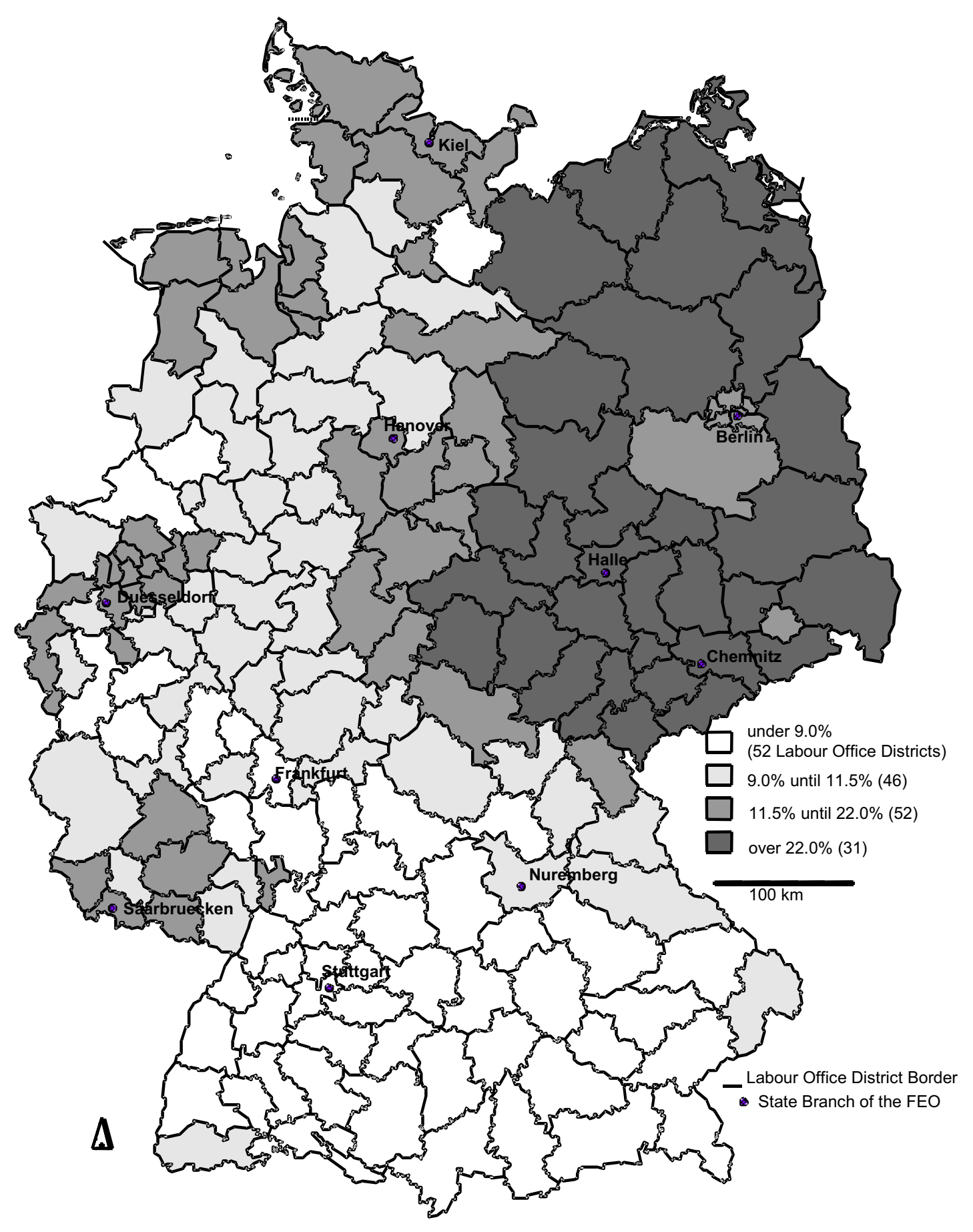

(a) The job seeker rate is defined as the unemployment rate extended by the rate of people participating in ALMP measures. 
Figure B.4: Relation Between Job Creation Schemes and Training Measures, 1999

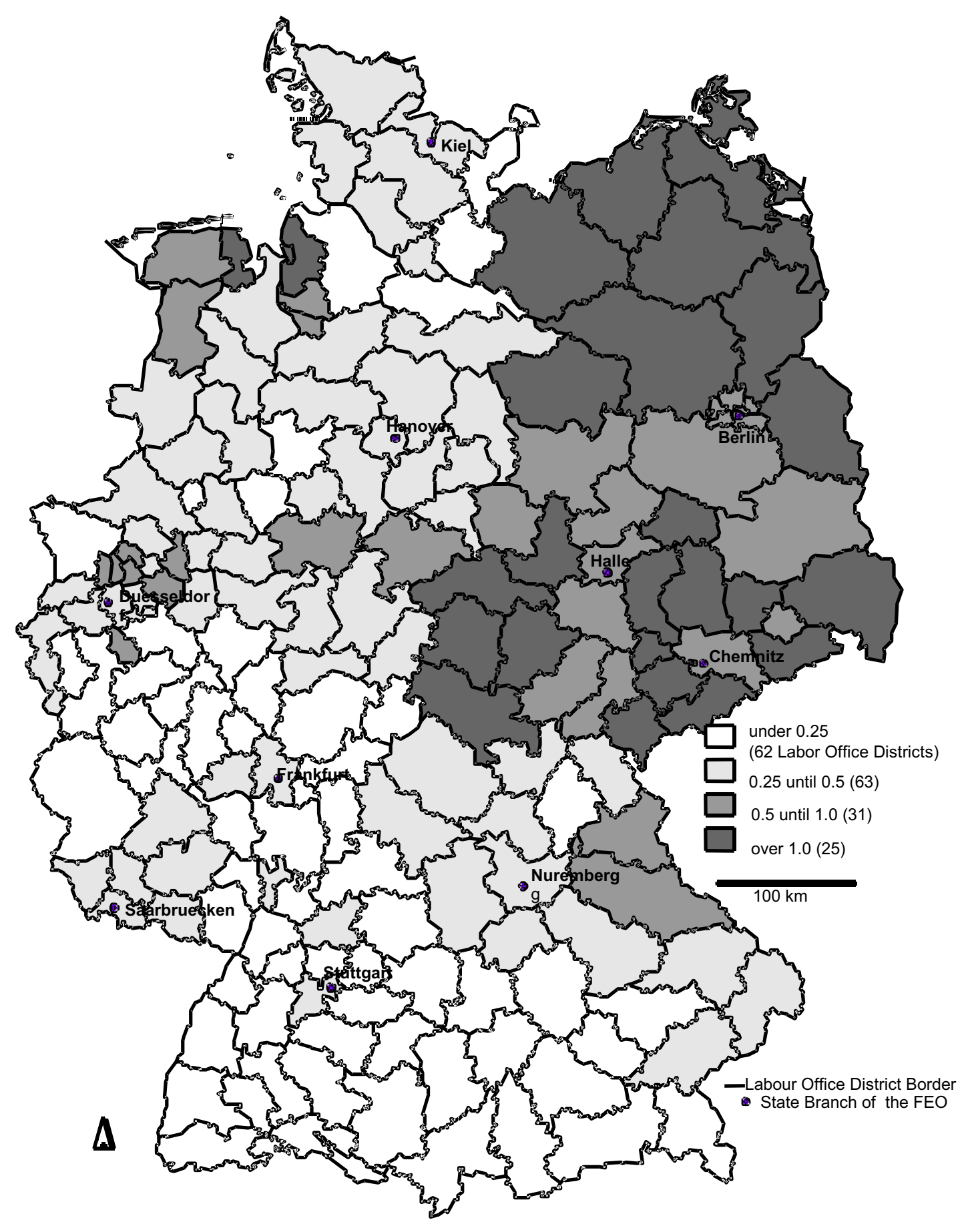




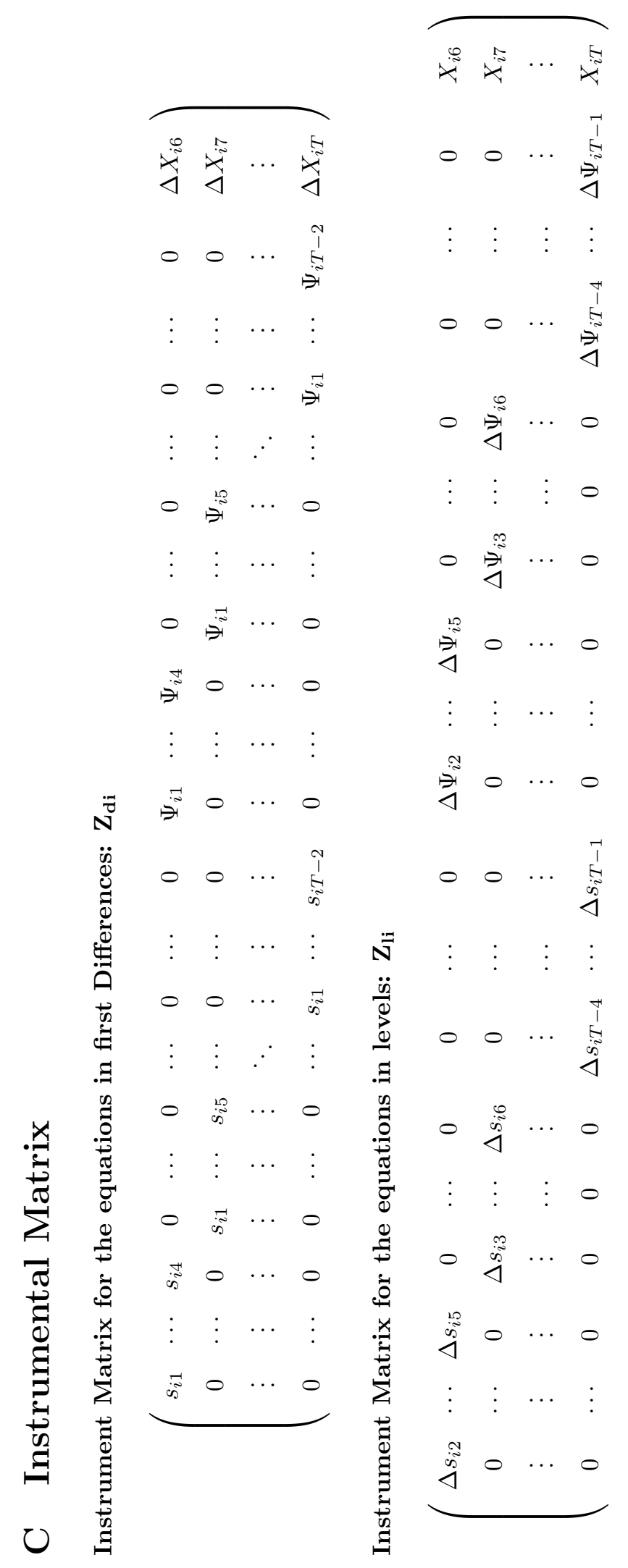




\section{References}

Ahn, S., And P. Schmidt (1995): "Efficient estimation of models for dynamic panal data," Journal of Econometrics, 68, 5-27.

Arellano, M., and S. Bond (1991): "Some Tests of Specification for Panel Data: Monte Carlo Evidence and an Application to Employment Equations," Review of Economic Studies, $58,277-297$.

(1998): "Dynamic Panal Data Estimation using DPD98 for Gauss,"
http://www.ifs.org.uk/staff/steve b.shtml.
BAILY, M., AND J. ToBIN (1977): "Macroeconomic Effects of Selective Public Employment and
Wage Subsidies," Brooking Papers on Economic Activity, 2.

Baltagi, B. (2001): Econometric Analysis of Panel Data. John Wiley and Sons, Chichester.

BLIEN, U. (2002): "Ein Arbeitsmarktgesamtindikator zur Mittelverteilung für die aktive Arbeitsmarktpolitik," Beiträge zur Arbeitsmarkt- und Berufsforschung, 250, forthcoming.

Blien, U., L. Blume, A. Eickelpasch, G. Geppert, V. Maierhofer, and W. Wolf (2002): "Die Entwicklung der ostdeutschen Regionen," Beiträge zur Arbeitsmarkt- und Berufsforschung, forthcoming.

Blundell, R., And S. Bond (1998): "Initial Conditions and Moment Restrictions in Dynamic Panel Data Models," Journal of Econometrics, 87, 115-143.

Blundell, R., S. Bond, and F. WindmeiJer (2000): "Estimation in Dynamic Panel Data Models: Improving on the Performance of the Standard GMM Estimators," Working Paper 00/12, The Institute for Fiscal Studies.

Boeri, T., And M. Burda (1996): "Active labor market policies, job matching and the Czech miracle," European Economic Review, 40, 805-817.

Bond, S. (2002): "Dynamic Panal Data Models: A Duide to Micro Data Methods and Practice," cemmap working Paper cwp09/02, The Institute for Fiscal Studies.

Bond, S., And F. WindmeiJer (2002): "Finite Sample Inference for GMM Estimatros in Linear Panel Data Models," cemmap working Paper cwp04/02, The Institute for Fiscal Studies.

Brinkmann, C. (1999): "Controlling and Evaluation of Employment Promotion and the Employment Services in Germany," IAB Labour Market Research Topics, 36.

Büttner, T., And H. Prey (1998): "Does Active Labour-Market Policy Affect Structural Unemployment? An Empirical Investigation for West German Regions, 1986-1993," Zeitschrift für Wirtschafts- und Sozialwissenschaften, 118, 389-413.

Bundesanstalt FüR Arbeit (2000): Daten zu den Eingliederungsbilanzen 1999. Nürnberg. (2002): Arbeitsmarkt 2001. Nürnberg.

CAlmfors, L. (1994): "Active Labour Market Policy and Unemployment - A Framework for the Analysis of Crucial Design Features," OECD Economic Studies, 22, 7-47.

Calmfors, L., and A. Forslund (1991): "Real-Wage Determination and Labour Market Policies: The Swedish Experience," The Economic Journal, 101 (408), 1130-1148.

Calmfors, L., A. Forslund, and M. Hemström (2002): "Does Active Labour Market Poicy Work? Lessons From The Swedish Experience," CESifo working Paper no. 675(4), CESifo. 
Calmfors, L., and H. LANG (1995): "Macroeconomic Effects of Active Labor Market Programmes in a Union-Wage-Setting Model," Economic Journal, 105 (430), 601-619.

Calmfors, L., and P. Skedinger (1995): "Does Active Labour-Market Policy Increase Employment? Theoretical Considerations and Some Empirical Evidence from Sweden," Oxford Review of Economic Policy, 11 (1), 91-109.

FAY, R. (1996): "Enhancing the Effectiveness of Active Labor Market Policies: Evidence from Programme Evaluations in OECD Countries," Labour Market and Social Policy Occasional Papers, OECD.

Fertig, M., And C. Schmidt (2000): "Discretionary Measures of Active Labour Market Policy - The German Employment Promotion Reform in Perspective," Working Paper, Department of Economics (Econometrics), University of Heidelberg.

Fitzenberger, B., and R. Hujer (2002): "Stand und Perspektiven der Evaluation der Aktiven Arbeitsmarktpolitik in Deutschland," Perspektiven der Wirtschaftspolitik, forthcoming 2002.

Fitzenberger, B., And S. Speckesser (2000): "Zur wissenschaftlichen Evaluation der Aktiven Arbeitsmarktpolitik in Deutschland," Mitteilungen aus der Arbeitsmarkt und Berufsforschung, Schwerpunktheft: Erfolgskontrolle aktiver Arbeitsmarktpolitik, 3, 532-549.

Forslund, A., And A. Krueger (1994): "An Evaluation of the Swedish Active Labor Market Policy: New and Received Wisdom," Working Paper No. 4802, NBER.

Greene, W. H. (2000): Econometric Analysis. New York University, New York.

Hagen, T., and V. Steiner (2000): Von der Finanzierung der Arbeitslosigkeit zur Förderung von Arbeit - Analysen und Empfehlungen zur Arbeitsmarktpolitik in Deutschland. Nomos Verlagsgesellschaft, Baden-Baden.

Heckman, J. (1999): "Accounting for Heterogeneity, Diversity and General Equilibrium in Evaluating Social Programs," Working Paper No.7230, National Bureau of Economic Research.

Heckman, J., R. LaLonde, and J. Smith (1999): "The Economics and Econometrics of Active Labor Market Programs," in Handbook of Labor Economics Vol.III, ed. by O. Ashenfelter, and D. Card, pp. 1865-2097. Elsevier, Amsterdam.

Holmlund, B., And J. Linden (1993): "Job Matching, Temporary Public Employment and Equilibrium Unemployment," Journal of Public Economics, 51, 329-343.

Hujer, R., and M. Caliendo (2001): "Evaluation of Active Labour Market Policy - Methodological Concepts and Empirical Estimates," in Soziale Sicherung in einer dynamischen Gesellschaft, ed. by I. Becker, N. Ott, and G. Rolf, pp. 583-617. Campus-Verlag.

Hujer, R., M. Caliendo, and D. Radic (2001): "Estimating the Effects of Wage Subsidies on the Labour Demand in West Germany Using the IAB Establishment Panel," ifo-Studien, 47(2), 163-199.

Hujer, R., and M. Wellner (2000): "The Effects of Public Sector Sponsored Training on Individual Employment Performance in East Germany," Discussion Paper No.141, IZA.

Jackman, R., C. Pissarides, and S. Savouri (1990): "Labour Market Policies and Unemployment in the OECD," Economic Policy, 5, 450-490.

Johnson, G., And R. LAyard (1986): "The Natural Rate of Unemployment: Explanation and Policy," in Handbook of Labor Economics. North-Holland. 
Krugman, P. (1991): Geography and Trade. MIT Press, Cambridge (Mass.).

Layard, R., and S. Nickell (1986): "Unemployment in Britain," Economica, Suppl.53, 121170.

LAYARd, R., S. Nickell, and R. Jackman (1991): Unemployment - Macroeconomic Performance and the Labour Market. Oxford University Press, New York.

Nickell, S. (1981): "Biases in Dynamic Models with Fixed Effects," Econometrica, 49 (6), $1417-1426$.

OECD (1993): Employment Outlook. Paris.

Pannenberg, M., and J. Schwarze (1998): "Labor Market Slack and the Wage curve," economics letters, 58, 351-354.

Pissarides, C. (2000): Equilibrium Unemployment Theory. MIT Press.

PREY, H. (1999): Wirkungen staatlicher Qualifizierungsmaßnahmen. Eine empirische Untersuchung für die Bundesrepublik Deutschland. Paul Haupt-Verlag, Bern, Stuttgart, Wien.

Ridder, G., and T. Wansbeek (1990): "Dynamic Models for Panel Data estimators," in Advanced Lectures in Quantitative Economics, ed. by R. van der Ploeg. Academic Press, New York.

Rubin, D. (1980): "Comment on Basu, D. - Randomization Analysis of Experimental Data: The Fisher Randomization Test," Journal of the American Statistical Association, 75, 591593.

Schmid, G., S. Speckesser, and C. Hilbert (2000): "Does Active Labour Market Policy Matter? An Aggregate Impact Analysis for Germany," in Labour Market Policy and Unemployment. Evaluation of Active Measures in France, Germany, The Netherlands, Spain and Sweden. Edward Elgar.

SELL, S. (1998): "Entwicklung und Reform des Arbeitsförderungsgesetzes als Anpassung des Sozialrechts an flexible Erwerbsformen," Mitteilungen aus der Arbeitsmarkt und Berufsforschung, 3, 532-549.

Smith, J. (2000): "A Critical Survey of Empirical Methods for Evaluating Active Labor Market Policies," Zeitschrift für Volkswirtschaft und Statistik, 136, No.3, 1-22.

StaAt, M. (1997): Empirische Evaluation von Fortbildung und Umschulung - Schriftenreihe des $Z E W$ 21. Nomos Verlagsgesellschaft, Baden-Baden.

Steiner, V., E. Wolf, J. Egeln, M. Almus, H. Schrumpf, and P. Feldotto (1998): Strukturanalyse der Arbeitsmarktentwicklung in den neuen Bundesländern. Nomos Verlagsgesellschaft, Baden-Baden.

Windmeijer, F. (2000): "A Finite Sample Corrextion for the Variance of Linear Two-Step Estimators," Working Paper 00/19, The Institute for Fiscal Studies. 